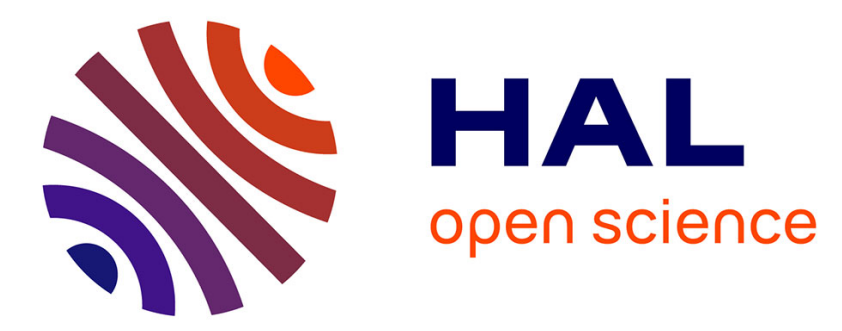

\title{
Lithium extraction from complex aqueous solutions using supported ionic liquid membranes
}

Guillaume Zante, Maria Yu Boltoeva, Abderrazak Masmoudi, Rémi Barillon, Dominique Trebouet

\section{- To cite this version:}

Guillaume Zante, Maria Yu Boltoeva, Abderrazak Masmoudi, Rémi Barillon, Dominique Trebouet. Lithium extraction from complex aqueous solutions using supported ionic liquid membranes. Journal of Membrane Science, 2019, 580, pp.62-76. 10.1016/j.memsci.2019.03.013 . hal-02272684

\section{HAL Id: hal-02272684 \\ https://hal.science/hal-02272684}

Submitted on 22 Oct 2021

HAL is a multi-disciplinary open access archive for the deposit and dissemination of scientific research documents, whether they are published or not. The documents may come from teaching and research institutions in France or abroad, or from public or private research centers.
L'archive ouverte pluridisciplinaire HAL, est destinée au dépôt et à la diffusion de documents scientifiques de niveau recherche, publiés ou non, émanant des établissements d'enseignement et de recherche français ou étrangers, des laboratoires publics ou privés.

\section{다)(1) $(5$}

Distributed under a Creative Commons Attribution - NonCommercial| 4.0 International 


\title{
Lithium extraction from complex aqueous solutions using supported ionic liquid membranes
}

\author{
Guillaume Zante ${ }^{\mathrm{a}, \mathrm{b},{ }^{*}}$, Maria Boltoeva ${ }^{\mathrm{a}}$, Abderrazak Masmoudi ${ }^{\mathrm{a}}$, Rémi Barillon ${ }^{\mathrm{a}}$, Dominique \\ Trébouet $^{\mathrm{a}}$ \\ a Université de Strasbourg, CNRS, IPHC UMR 7178, F-67000 Strasbourg, France \\ ${ }^{\mathrm{b}}$ ADEME, 20 Avenue du Grésillé, 49004 Angers Cédex 01, France \\ * Corresponding author \\ E-mail address: guillaume.zante@etu.unistra.fr
}

\begin{abstract}
This work evaluates the feasibility to separate selectively lithium cations from complex aqueous solutions containing sodium, cobalt and nickel ions using a supported liquid membranes (SLMs) impregnated with a mixture of hydrophobic ionic liquid 1-butyl-3methylimidazolium bis(trifluoromethylsulfonyl)imide $\left(\left[\mathrm{C}_{4} \mathrm{mim}\right]\left[\mathrm{NTf}_{2}\right]\right)$ and tri- $n$-butyl phosphate (TBP) as the carrier. Various hydrophobic room-temperature ionic liquids (ILs), namely with dialkyl imidazolium, quaternary ammonium and phosphonium cations, were tested as supporting phase in hydrophobic porous polyvinylidene fluoride (PVDF) membranes. Membrane impregnation studies show that the mass uptake is following the density of the organic phase. The stability experiments indicate that the losses of IL in the surrounding aqueous phases are related to its aqueous solubility and could be reduced by the addition of salt in the feed and/or stripping phase. Lithium membrane extraction and selective separation from aqueous complex solutions containing large amounts of sodium ions has been demonstrated. The selective separation of lithium from cobalt and nickel ions as well as from magnesium in acidic aqueous solutions has shown promising results. The results obtained in present study indicate that the use of hydrophobic IL for SLM preparation allows the facilitated transport of lithium ions.
\end{abstract}

Keywords: Supported liquid membrane (SLM), Ionic liquids, Tri-n-butyl phosphate (TBP) carrier, Lithium, Membrane transport

\section{Introduction}

Lithium ( $\mathrm{Li}$ ) is the lightest metal and its unique physicochemical properties have made of it the main component of lithium-ion batteries. Worldwide lithium production has known a constant increase in the last decade [1] with the growth in the consumption of electronic devices, and this increase is expected to continue to rise in a near future with the electrification of the car fleet [2]. To meet this growing demand, various sources of lithium are currently used, such as lithium brines [3] or lithium ores [4], in which however the lithium content is quite low. Various other sources both primary and secondary are being evaluated, and among them geothermal waters [5] and the recycling of spent lithium-ion batteries [6] are the most promising. However the extraction and separation of lithium remains challenging task, mainly due to the complex matrices in which lithium can be found. Low concentrations of lithium have to be removed from solutions containing large amounts of other metals. For example, the separation of lithium from sodium and magnesium is 
challenging in brines and geothermal waters [7-8]. These aspects have outlined the need for efficient and selective methods of extraction for the lithium ions. Several techniques are used to extract and separate lithium, such as adsorption using solid sorbents, solvent (liquidliquid) extraction or membrane-based technologies [9].

Supported liquid membrane based on ionic liquids (SLM) is a promising separation technology for various chemical species, such as organic compounds or gas mixtures [10-12]. SLMs have been also applied as a pre-concentration method for metal ions [13-14], or for the selective removal of toxic or valuable metals from aqueous solutions [15-16]. This technique consists of an organic phase immobilized into the pores of a polymeric support, placed between two aqueous phases, i.e. three phases are involved. The first phase is an aqueous "feed" solution, containing the target metal ions, the second aqueous solution is a "receiving" (or "stripping") phase in which the target metal ions are released. For the separation of highly hydrophilic metal ions, the organic phase should contain a carrier (organic extracting molecule) that selectively binds to a target metal ion and forms lipophilic metal-organic ligand species. This metal-carrier complex is then diffusively transported across the supported organic phase and finally the metal ion is released in the receiving phase. The transport of metal ions across a SLM is a continuous permeation process that combines simultaneously the extraction and stripping steps, besides with reduced volumes of chemical reagents. In fact, the actual hydrometallurgical processes imply the use of large amounts of organic solvents and several steps to obtain a good selectivity among the various metals and sufficient extraction yields. The advantages of SLMs could lead to an intensification of the hydrometallurgical processes currently used, such as liquid-liquid extraction. For example, the opportunity of using membrane extraction systems for the recycling of metals has been recently highlighted [17].

However, the lack of stability of the SLMs limits their application at an industrial scale. These instabilities have been attributed to several phenomena [18-20] (such as solubility of the organic phase in the adjacent aqueous phases or pressure difference over the membrane). These phenomena lead to the loss of the organic phases into the aqueous phases, causing a decrease in the process performance and affecting the environmental advantages of the technique. Moreover, a good stability of the supported liquid membrane is indispensable to obtain an efficient and complete transport of the target metal. The use of ionic liquids (ILs) could overcome this limitation because of their unique properties, such as high viscosity or negligible vapor pressure [21]. Moreover, the non-flammability and the absence of evaporation of these low temperature molten salts (generally, m.p. $<100{ }^{\circ} \mathrm{C}$ ) are of great interest when using these chemicals in a large scale. Among the specific properties of ILs, one of the most interesting is the possibility to tune their physicochemical properties by selecting among the various ions constituting the ionic liquids [22].

In this work, we first aim to explore the influence of physicochemical proprieties of hydrophobic ionic liquids on the impregnation and stability of SLMs, then to apply this technique to lithium separation from the aqueous solutions. The ionic liquids are chosen from various families, namely dialkyl imidazolium with various alkyl chain length, quaternary ammonium and phosphonium based ILs were examined. This variety affords us a large range of physicochemical properties such as density, viscosity and aqueous solubility that will influence the impregnation and the stability of the supported liquid membrane. The second part of this work will be at the interface between solution chemistry and process design. An electrically neutral and well-known extractant, tri- $n$-butyl phosphate (TBP), often used in 
SLM separation [23-25], has been used as a carrier. The combination of TBP and imidazolium based ionic liquids has shown previously promising results for the selective solvent extraction of lithium [26-27]. The extraction of lithium is not possible with TBP alone. But the addition of a small proportion of ionic liquid allows the extraction of lithium to the organic phase. This extraction proceeds by an exchange between the lithium ion and the ionic liquid cation. In present study a mixture of TBP and IL is applied for the extraction and separation of lithium ions from complex aqueous synthetic solutions using a supported liquid membrane.

\section{Materials and methods}

\subsection{Reagents and membranes}

Five hydrophobic polyvinylidene fluoride (PVDF) membranes with different nominal pore sizes and diameters have been used as polymeric supports. Table 1 shows the suppliers and the parameters of these membranes.

\section{Table 1.}

Physical properties of membranes studied in this work and suppliers.

\begin{tabular}{cccc}
\hline Diameter $(\mathrm{cm})$ & Thickness $(\mu \mathrm{m})$ & $\begin{array}{c}\text { Nominal pore size } \\
(\mu \mathrm{m}) / \text { porosity }(\%)\end{array}$ & Supplier \\
\hline 2.5 & 150 & $0.45 / 85$ & Merck-Millipore \\
\hline 2.5 & 150 & $0.22 / 85$ & Merck-Millipore \\
\hline 2.5 & 50 & $0.1 /-$ & Sterlitech \\
\hline 2.5 & 50 & $0.02 /-$ & Sterlitech \\
\hline 5.5 & 125 & $0.45 / 75$ & Merck-Millipore \\
\hline
\end{tabular}

The hydrophobic room-temperature ionic liquids are purchased from Solvionic (France), and used without further purification. The physicochemical properties of ILs used in present work are summarized in the Table 2. 
Table 2.

Ionic liquids used in this study (a): surface tension data at $298 \mathrm{~K}$ from reference [28].

\begin{tabular}{|c|c|c|c|c|c|}
\hline Ionic liquid & Abbreviation & $\begin{array}{l}\text { Purity } \\
\text { (\%) }\end{array}$ & Density & $\begin{array}{l}\text { Viscosity } \\
\text { (cP) }\end{array}$ & $\begin{array}{l}\text { Surface } \\
\text { tension } \\
(\mathrm{mN} / \mathrm{m})\end{array}$ \\
\hline $\begin{array}{l}\text { 1-Ethyl-3-methylimidazolium } \\
\text { bis(trifluoromethylsulfonyl)imide }\end{array}$ & {$\left[\mathrm{C}_{2} \mathrm{mim}\right]\left[\mathrm{NTf}_{2}\right]$} & 99.5 & 1.50 & 24.5 & 35.2 \\
\hline $\begin{array}{l}\text { 1-Butyl-3-methylimidazolium } \\
\text { bis(trifluoromethylsulfonyl)imide }\end{array}$ & {$\left[\mathrm{C}_{4} \mathrm{mim}\right]\left[\mathrm{NTf}_{2}\right]$} & 99.5 & 1.42 & 61.1 & 33.2 \\
\hline $\begin{array}{l}\text { 1-Hexyl-3-methylimidazolium } \\
\text { bis(trifluoromethylsulfonyl)imide }\end{array}$ & {$\left[\mathrm{C}_{6} \mathrm{mim}\right]\left[\mathrm{NTf}_{2}\right]$} & 99.5 & 1.33 & 90.1 & 32.5 \\
\hline $\begin{array}{l}\text { 1-Octyl-3-methylimidazolium } \\
\text { bis(trifluoromethylsulfonyl)imide }\end{array}$ & {$\left[\mathrm{C}_{8} \mathrm{mim}\right]\left[\mathrm{NTf}_{2}\right]$} & 99.5 & 1.31 & 104 & 29.5 \\
\hline $\begin{array}{l}\mathrm{N} \text {-Trimethyl-N-butylammonium } \\
\text { bis(trifluoromethylsulfony)limide }\end{array}$ & {$\left[\mathrm{N}_{1114}\right]\left[\mathrm{NTf}_{2}\right]$} & 99.5 & 1.41 & 124 & 38.1 \\
\hline $\begin{array}{l}\text { Trihexyl(tetradecyl)phosphonium } \\
\text { bis(trifluoromethylsulfony)limide }\end{array}$ & {$\left[\mathrm{P}_{66614}\right]\left[\mathrm{NTf}_{2}\right]$} & 99.5 & 1.06 & 292 & 28.9 \\
\hline
\end{tabular}

Tri- $n$-butyl phosphate (TBP, purity $>99 \%$ ) was purchased from Acros Organics. The chemical structures of TBP and ionic liquids used are shown in Figure 1. Sodium chloride (purity 99.5\%), sodium sulfate (purity $99 \%$ ), sodium perchlorate, magnesium chloride and lithium chloride (purity $99 \%$ ) were supplied from Merck and used without further purification. Lithium sulfate, cobalt sulfate and nickel sulfate (purity $>99 \%$ ) purchased from Merck were used without further purification. Sulfuric acid of analytical grade was purchased from Thermo-Fischer Scientific. De-ionized water is obtained after percolation through activated carbon and ion exchange resins (type ORC and type R3 resin from Thermo-Fischer Scientific), and used for the preparation of all aqueous solutions. 


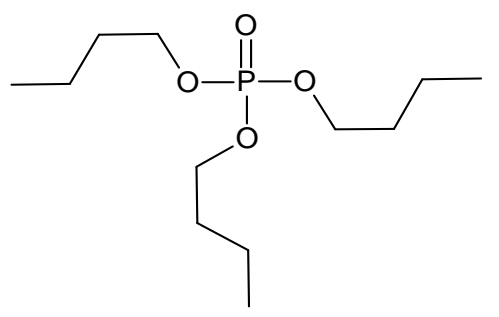

Tri-n-butyl phosphate (TBP)
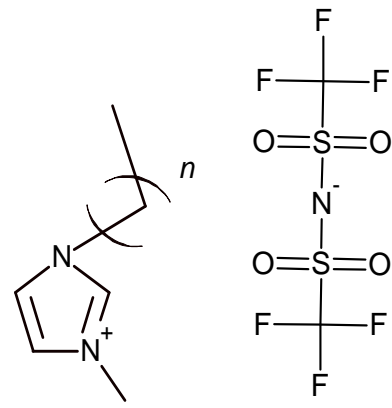

$\left[\mathrm{C}_{\mathrm{n}} \operatorname{mim}\right]\left[\mathrm{NTf}_{2}\right]$

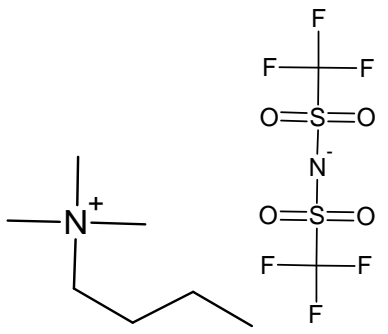

$\left[\mathrm{N}_{1114}\right]\left[\mathrm{NTf}_{2}\right]$<smiles>O=S(=O)(NNS(=O)(=O)C(F)(F)F)C(F)(F)F</smiles>

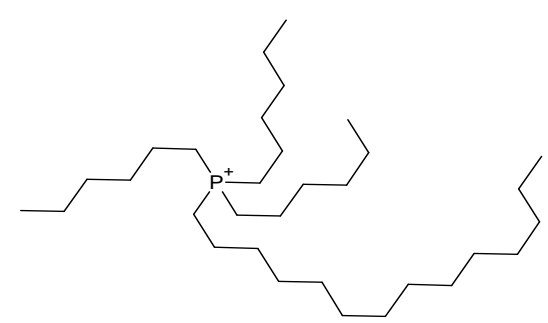

$\left[\mathrm{P}_{66614}\right]\left[\mathrm{NTf}_{2}\right]$

Figure 1. Chemical structures of Tri-n-butyl phosphate and of the various ionic liquids used in this study.

\subsection{Preparation of supported liquid membranes}

Supported liquid membranes were prepared with two distinct methods. In the direct immersion method, the membrane was immersed into $2 \mathrm{~mL}$ of the ionic liquid. The pressure method has been previously described by Hernádez-Fernández et al. [29]. Briefly, the membrane sheet was placed in a $10 \mathrm{~mL}$ Amicon ${ }^{\mathrm{TH}}$ ultrafiltration unit (Merck) and then submerged by $3 \mathrm{~mL}$ of the ionic liquid. A compressed air pressure ( 2 bars) was applied until a thin layer of ionic liquid appears at the surface of the membrane. The operation was repeated three times to ensure a complete filling of the pores. For both procedures, the membrane film was left to dry overnight vertically in a Petri dish before use.

\subsection{Membrane impregnation study}

To determine the amount of immobilized ionic liquid or TBP/IL mixture, the membranes were weighed before and after impregnation procedure using a Mettler Toledo AG245 instrument (precision=0.02 $\mathrm{mg}$ ), and the mass uptake ( $\mathrm{g}$ of ionic liquid/g of membrane) was calculated according to the following equation (Eq. (1)).

$$
\text { Mass uptake }=\frac{m_{1}-m_{0}}{m_{0}}
$$

where $m_{0}$ and $m_{1}$ is the mass $(\mathrm{g})$ of dry and impregnated membrane, respectively. The membranes used for the impregnation and stability studies have a diameter of $2.5 \mathrm{~cm}$.

\subsection{Stability and transport experiments}

After impregnation and drying procedure, the membrane film with immobilized IL was clamped between two compartments of a glass membrane contactor (Verlabo, France) using two Teflon O-rings. The compartment volumes for feed and stripping solutions were $250 \mathrm{~mL}$. 
The aqueous phases were magnetically stirred at ambient temperature at $50 \mathrm{rpm}$ with glass agitators containing a magnet in each compartment. The membrane loss rate was determined by mass balance before and after contact with the aqueous phases, according to the following equation (Eq. (2)) [30]:

$$
\text { Loss rate }(\%)=\frac{m_{1}-m_{2}}{m_{1}-m_{0}} \times 100
$$

Where $m_{2}$ is the mass of supported ionic liquid membrane (g) after one hour of contact with aqueous solutions. The membrane was left to dry for at least several hours before weighing.

For the metal transport experiments, the compartments are filled with the aqueous solutions prepared by dissolving gravimetrically the metal salts in water. Membrane films with a diameter of $5.5 \mathrm{~cm}$ were used, providing an effective surface of exchange of $17.8 \mathrm{~cm}^{2}$. The organic phase embedded into the membrane was made of TBP $(90 \% \mathrm{v} / \mathrm{v})$ and $\left[\mathrm{C}_{4} \mathrm{mim}\right]\left[\mathrm{NTf}_{2}\right](10 \% \mathrm{v} / \mathrm{v})$. This composition of the organic phase yields the best extraction efficiency for lithium [27]. The pH of the aqueous solutions was measured using a WTW pH196 apparatus.

\subsection{UV-vis measurements}

The imidazolium cation associated to the $\left[\mathrm{NTf}_{2}\right]$ anion in the aqueous solution is characterized by an absorption band at $\lambda_{\max }=211 \mathrm{~nm}$ [31-32], and with an extinction coefficient of $4407 \mathrm{~L} \cdot \mathrm{mol}^{-1} \cdot \mathrm{cm}^{-1}$ [31]. The UV-vis absorption spectra have been recorded at room temperature with a UV-PC 2401 apparatus (Shimadzu) using a quartz cell (optical path length $1 \mathrm{~cm}$ ).

\subsection{Determination of the metal content in the aqueous phases and calculation of the permeation coefficient}

During the metal transport experiments, aqueous samples of the feed and receiving solutions were withdrawn periodically and diluted appropriately before analysis. The metal content in these samples was determined using optical emission spectrometry (ICP-OES) on a Varian 720-ES apparatus.

The transport of the metal ion through the liquid membrane was monitored as the rate of decrease in the concentration of the metal ion in the source phase or the rate of increase in the concentration of the metal ion in the receiver phase. The permeability coefficient for the transport of the metal ion was calculated by the following equation (Eq. (3)) [33]:

$\ln \frac{C_{f, t}}{C_{f, 0}}=-\frac{A}{V} \times P \times t$

where $C_{f, t}$ and $C_{f, 0}$ denotes the current concentration of metal ion in source phase at elapsed $t$ and time zero; $A, V$ and $P$ represent effective surface area $\left(\mathrm{cm}^{2}\right)$ of membrane (surface area*porosity), volume of feed solution $(\mathrm{mL})$ and permeability of metal ion through the membrane $\left(\mathrm{cm} \cdot \mathrm{s}^{-1}\right)$, respectively. A linear fit of $\ln \left(C_{f, t} / C_{f, 0}\right)$ versus time must give a straight line with slope equal to $-P^{*} A$ / V. From the slope of fitted line, the permeability coefficient $(P)$ was calculated. The ion flux $\left(\mathrm{J}, \mathrm{mol} \cdot \mathrm{m}^{-2} \cdot \mathrm{s}^{-1}\right)$ can be calculated using the following equation [33] :

$\mathrm{J}=\mathrm{PxC}_{0}$

Where $C_{0}$ is the initial lithium concentration $\left(\mathrm{mol}^{-1} \mathrm{~L}^{-1}\right.$ ) in the feed solution. 


\section{Results and discussion}

\subsection{Membrane impregnation}

\subsubsection{Influence of density on the impregnation}

Supported ionic liquid membranes were prepared with both the direct immersion and pressure methods. Prior SLMs preparation, we examined the impregnation kinetics with the direct immersion method. The results obtained show that the membrane mass uptake does not evolve anymore after 30 minutes of impregnation, for all of the ionic liquids (IL) studied in present work. Moreover, the influence of the preparation method on the mass uptake in IL was also studied. The results showed the same mass uptakes (less than $10 \%$ of difference) in IL as those obtained with the direct immersion method. As a result, direct immersion during 30 minutes was retained for the further preparation of SLMs.

As long as the surface tension of IL (Table 2 ) is lower or not much higher than that of the PVDF membrane, a good impregnation is obtained, and the application of a pressure is not needed (critical surface tension of PVDF is $36.5 \mathrm{mN} \cdot \mathrm{m}^{-1}$ [34]). Moreover, it has been observed that the surface tension of the diluent has to be lower than the critical surface tension of the support in order to favor membrane stability [35].

However, differences are observed in the membrane mass uptakes obtained with various ionic liquids. The order of the mass uptake could be related to the ionic liquid viscosity and to the method of preparation of the SLM [36]. Figure 2 shows the mass uptake obtained for several liquid membranes prepared with various ILs. In our experimental conditions, the mass uptake is a linear function of the ionic liquid density, as already mentioned by Dahi et al. [11]. This result was confirmed using the pure organophosphorus compound, namely tri$n$-butyl phosphate, with a low mass uptake due to its low density. 


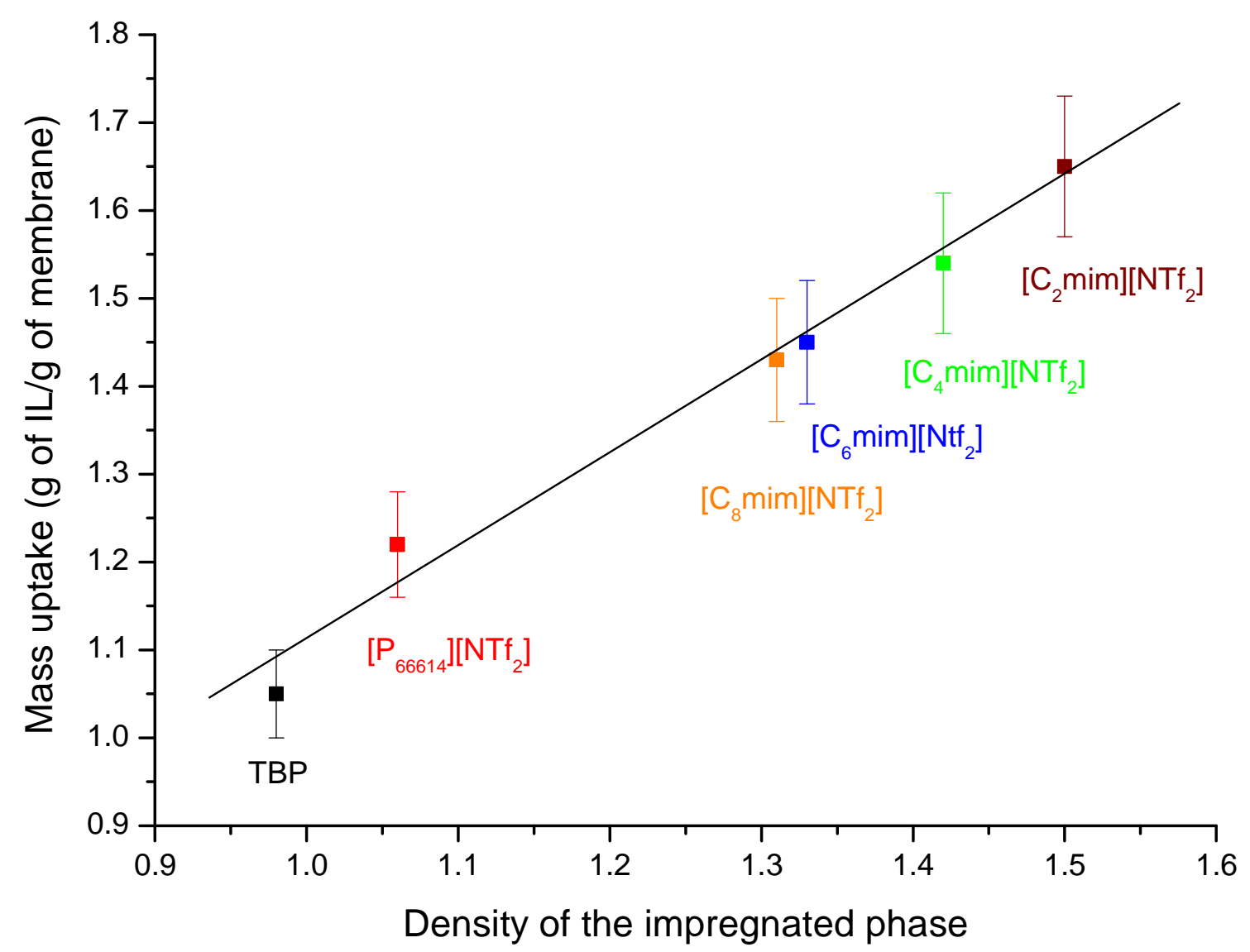

Figure 2. Membrane mass uptake (g of IL/g of membrane) for different organic phases as a function of the organic phase density

\subsubsection{Effect of the support's pore size}

The membrane mass uptake for three ionic liquids as a function of the support nominal pore size is shown in Figure 3. It can be seen in this figure that the mass of ionic liquid immobilized is increasing with a reduced pore size. For all the ionic liquids used, the mass uptake is higher when the nominal pore size of the support is low.

Even with a reduced thickness of the membrane, the mass uptake remains elevated. This could be attributed to the uncomplete filling of the largest micropores according to previous studies in which various supports impregnated with ionic liquids are observed with scanning electron microscopy images $[11,16,21]$. 


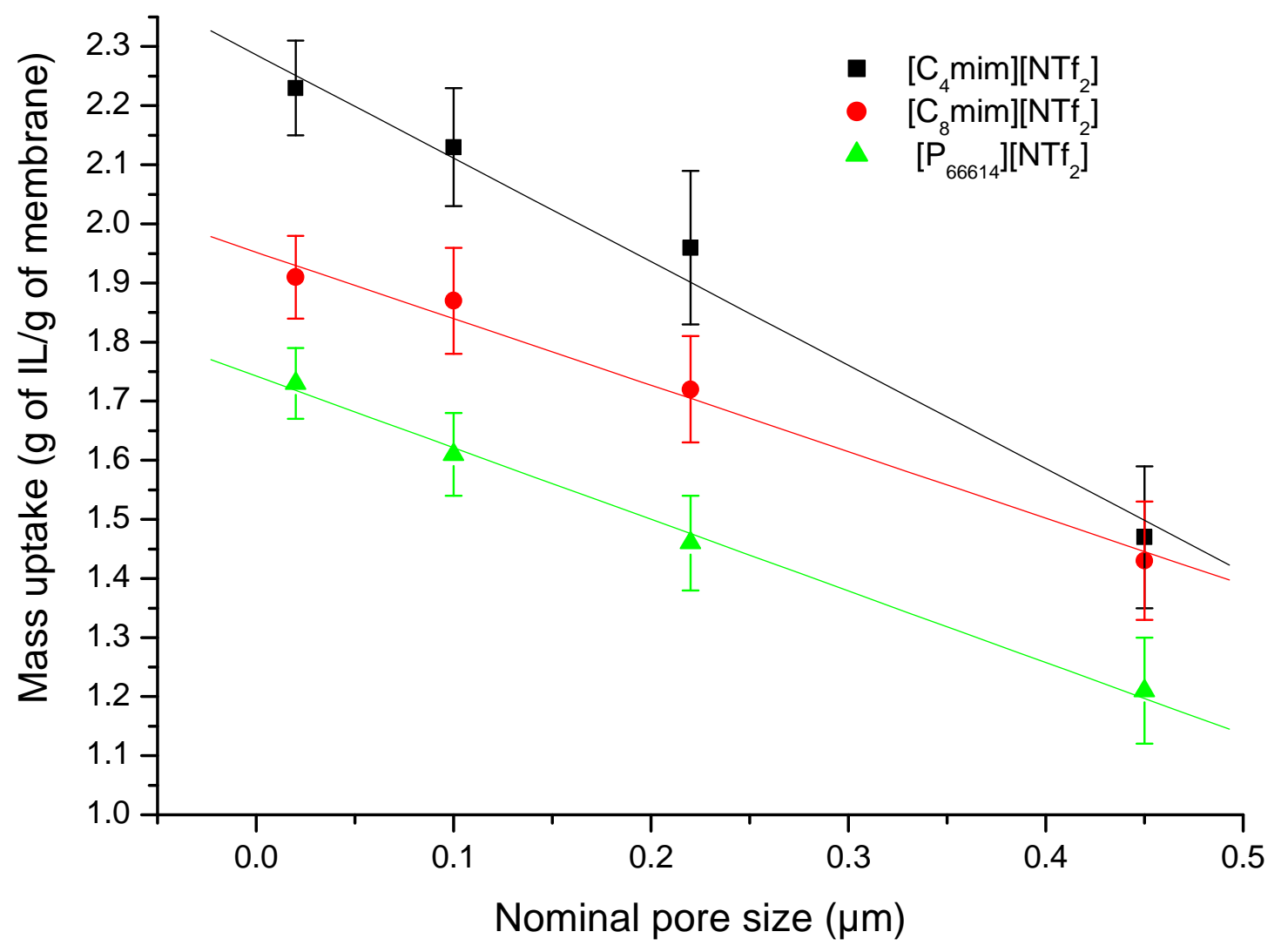

Figure 3. Membrane mass uptake ( $\mathrm{g}$ of $\mathrm{IL} / \mathrm{g}$ of membrane) for various ionic liquids as a function of the membrane nominal pore size $(\mu \mathrm{m})$

\subsection{Membrane stability}

\subsubsection{Effect of the ionic liquid solubility in water}

The membrane stability studies were carried out at ambient temperature, with the glass compartments filled with distilled water. The comparison of membrane loss rates for various ionic liquids is shown in Figure 4. The losses can not be attributed to an insufficient viscosity of the ionic liquid, because the viscosity of the $\left[\mathrm{N}_{1114}\right]\left[\mathrm{NTf}_{2}\right]$ ionic liquid $(124 \mathrm{cP})$ is twice the viscosity of the $\left[\mathrm{C}_{4} \mathrm{mim}\right]\left[\mathrm{NTf}_{2}\right](60.5 \mathrm{cP})$ and the losses are higher with the ammonium ionic liquid rather than with the imidazolium one. The high viscosity of the ionic liquids is not sufficient to retain them in the membrane. 


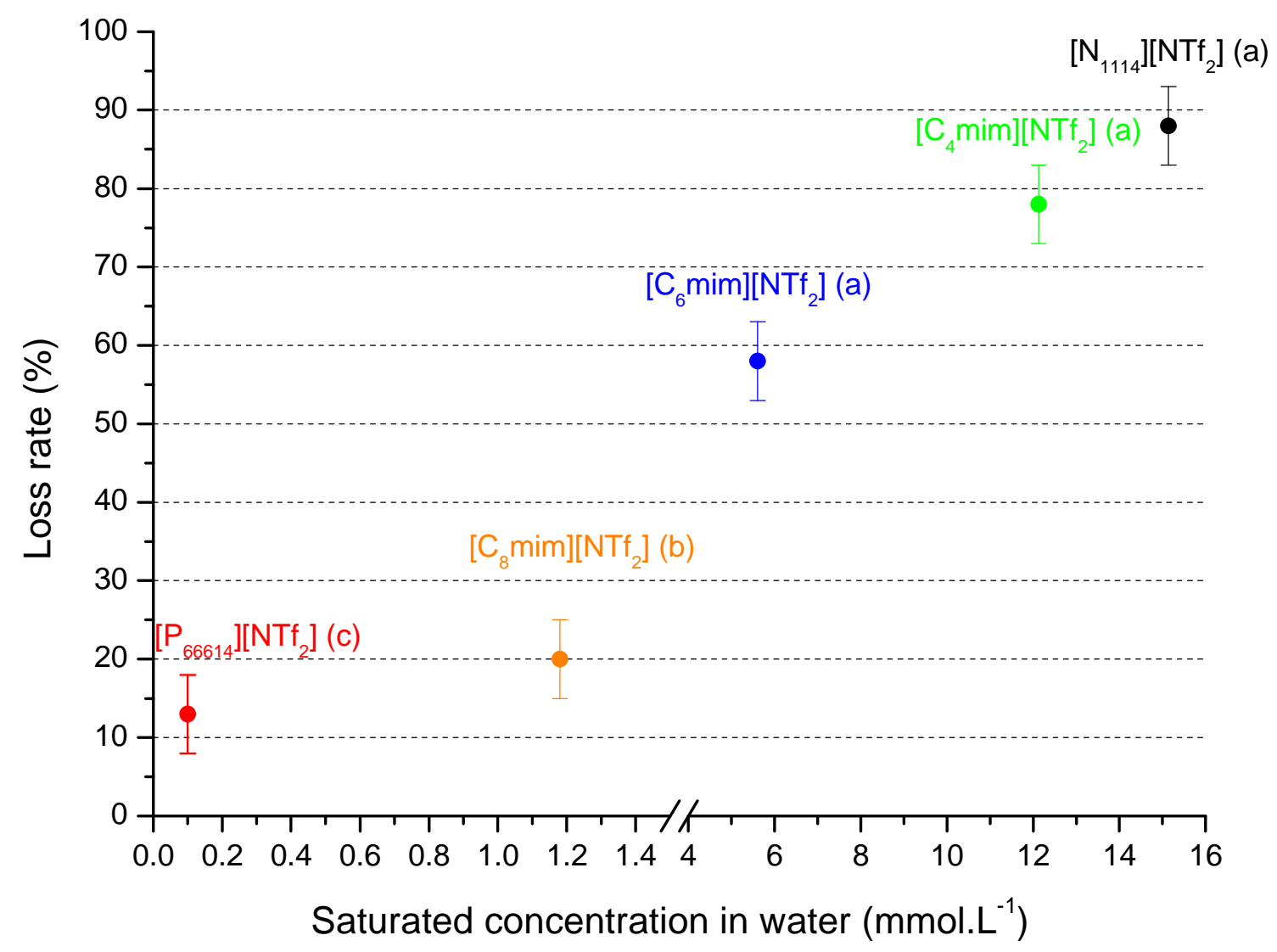

Figure 4. Membrane loss rate after one hour of contact in de-ionized water as a function of the lonic liquid saturated concentration in water. X Axis: break between 1.4 and $4 \mathrm{mmol}^{-1}$. Saturated concentrations of ionic liquid in water from (a): reference [37] (b): reference [38] (c): value calculated (indicated value 10-80 ppm) from reference [39]

However, the losses seem to be dependent on the ionic liquid solubility in the surrounding phases. The losses are much less important with a reduced solubility of the ionic liquid in water. For the highly hydrophobic $\left[\mathrm{P}_{66614}\right]\left[\mathrm{NTf}_{2}\right]$ ionic liquid, only $13 \%$ of the liquid membrane mass is lost after one hour of contact in distilled water. It can be concluded that among the various parameters that can affect the membrane stability, the solubility of the organic phase into the surrounding aqueous phases is the main mechanism of degradation, and the organic phase solubility in water must be as low as possible. 


\subsubsection{Addition of a salting-out agent}

The addition of an electrolyte in an aqueous phase is known to have an effect on the hydrophobic ionic liquids' solubility in water [39-43]. Figure 5 shows the membrane loss rate with the $\left[\mathrm{C}_{4} \mathrm{mim}\right]\left[\mathrm{NTf}_{2}\right]$ ionic liquid after one hour of contact in water, and with various concentrations of various sodium salts (sodium perchlorate, sodium chloride, sodium sulfate and sodium carbonate).

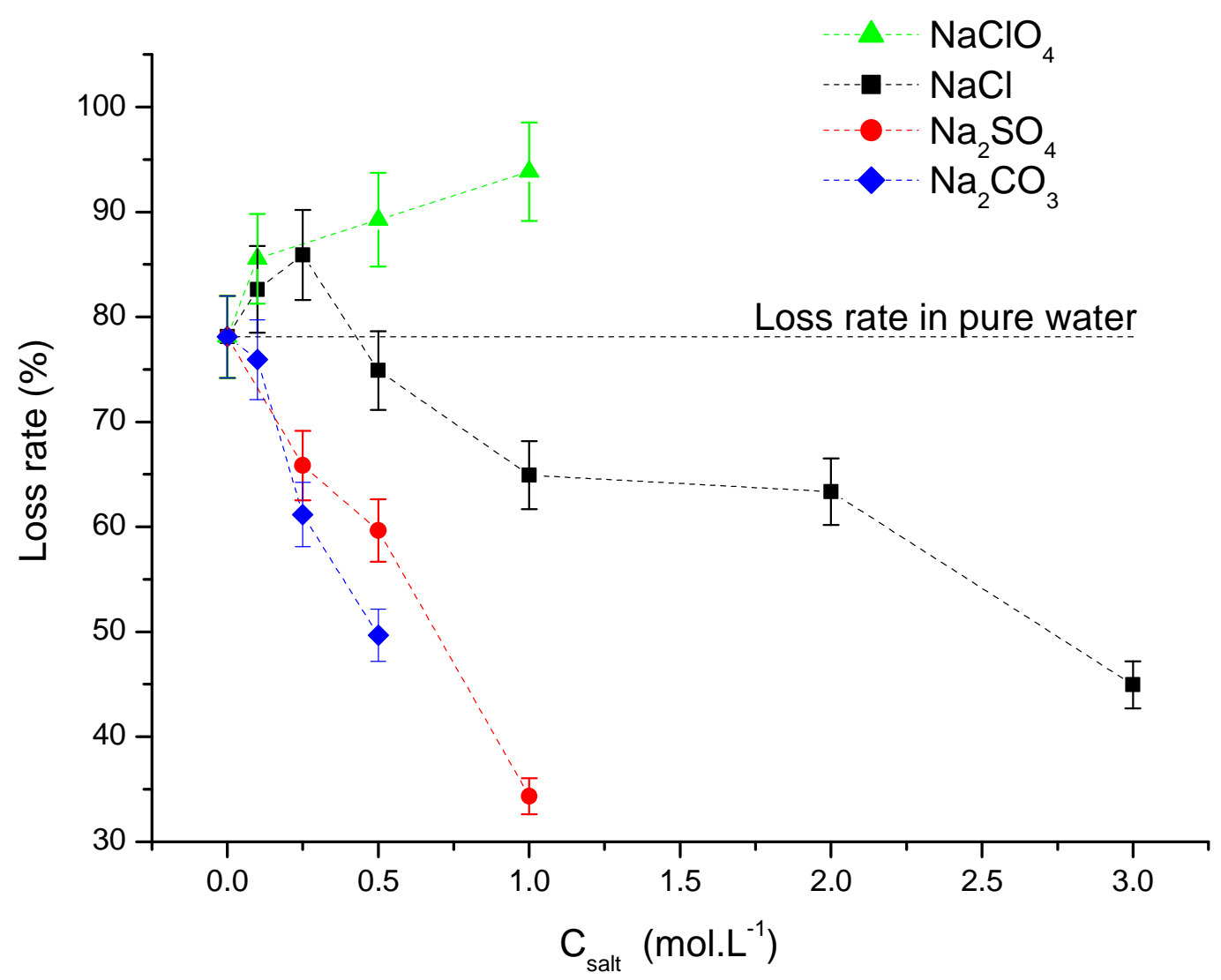

Figure 5. Membrane loss rate after one hour of contact with aqueous solution of several sodium salts at various concentrations. $\left[\mathrm{C}_{4} \mathrm{mim}\right]\left[\mathrm{NTf}_{2}\right]$ ionic liquid. Dot horizontal line: loss rate without addition of salt. The lines are drawn for clarification purpose

Different behaviors are observed with the various sodium salts used in the aqueous phases. For the sodium sulfate salt, the membrane loss rate is lower than in pure water, whatever the concentration used in the aqueous phase. For salts containing strongly hydrated ions like sulfates or carbonates, the solubility of the ionic liquid is decreased. The addition of this kind of salts results in an increase of entropy due to the binding of water molecules in the salts' anion and cation hydration sphere, thus reducing the ionic liquid solubility in water. The role of the anion is more important because the hydration sphere of an anion is always larger than the hydration sphere of a cation.

However, for salts rather lipophilic, (containing poorly hydrated ions) like sodium perchlorate, the membrane loss rate is increased at any concentration of salt. With these salts, the solubility of the ionic liquid is increased [39, 42], due to the binding of the anion and cation of the salt to the hydrophobic moiety of the ionic liquid, leading to an enthalpic effect [43]. For salts considered as "intermediate" in the Hoffmeister series, like sodium chloride, the enthalpic effect leads to an increase in the membrane loss rate at low concentrations of salts. But at a concentration of 0.5 mol. $\mathrm{L}^{-1}$ of sodium chloride, a decreased 
in the membrane loss rate is observed and at $3 \mathrm{~mol}^{-\mathrm{L}^{-1}}$ of sodium chloride, the losses are lower than the losses in pure water, due to the entropic effect. For the four sodium salts considered, at a concentration of $0,5 \mathrm{~mol}^{-1} \mathrm{~L}^{-1}$, it can be seen that the losses of the liquid membrane phase are in the order:

$\mathrm{CO}_{3}{ }^{2-}<\mathrm{SO}_{4}{ }^{2-}<\mathrm{Cl}^{-}<\mathrm{ClO}_{4}{ }^{-}$, thus following the same trend as the Hofmeister series.

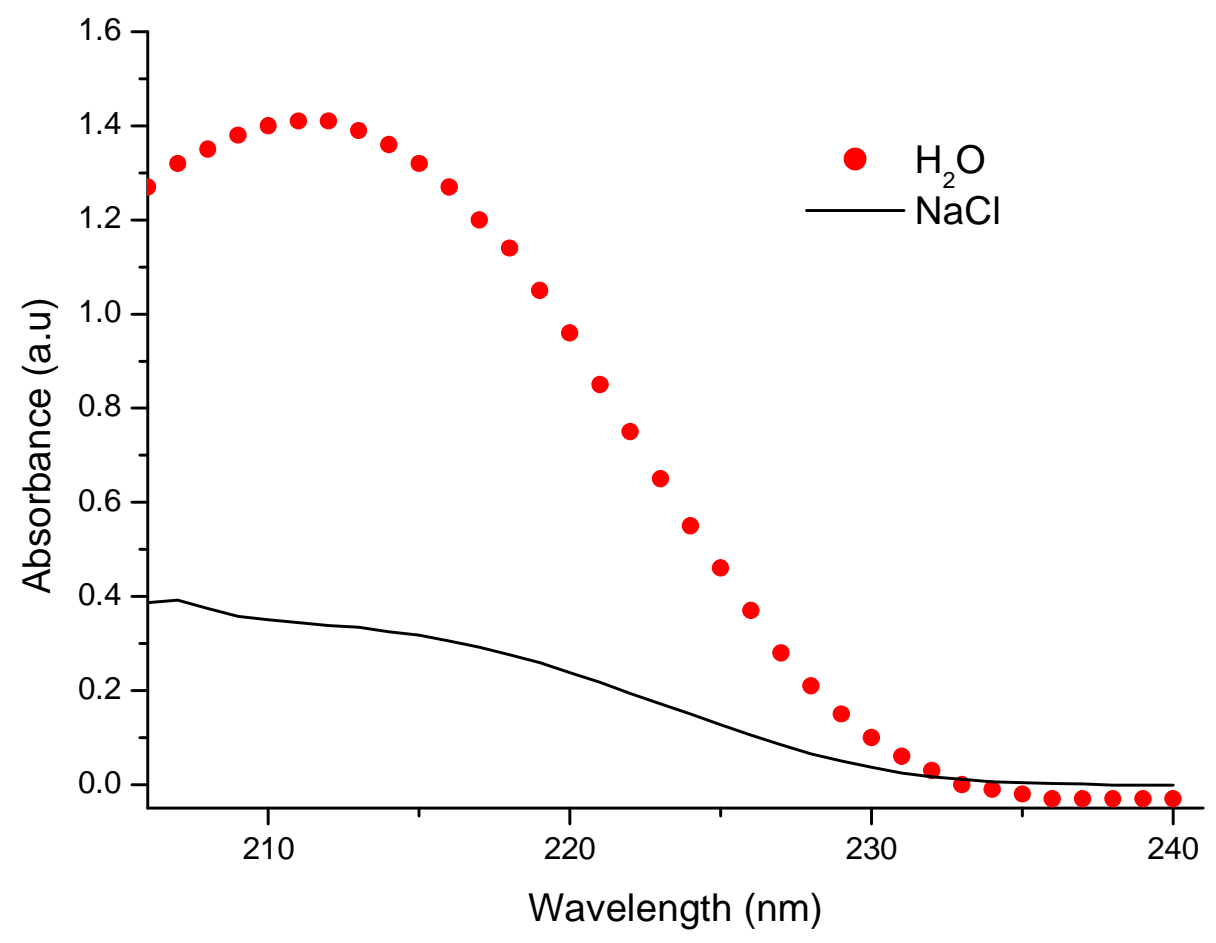

Figure 6. UV-vis spectra after one hour of contact. $\left[\mathrm{C}_{4} \mathrm{mim}\right]\left[\mathrm{NTf}_{2}\right]$ ionic liquid. Straight line: compartment filled with $\mathrm{NaCl} 3 \mathrm{~mol} / \mathrm{L}$; Dot line: compartment filled with distilled

The salting-out effect is confirmed by the UV-vis spectra of the $\left[\mathrm{C}_{4} \mathrm{mim}\right]$ cation (figure 6$)$. The membrane is impregnated with the $\left[\mathrm{C}_{4} \mathrm{mim}\right]\left[\mathrm{NTf}_{2}\right]$ ionic liquid and placed between two compartments, the first filled with distilled water, the second with a $3 \mathrm{~mol} / \mathrm{L}$ sodium chloride solution. The UV-vis spectra recorded in each compartment after one hour of contact shows a larger absorption in the compartment filled with distilled water, indicating that the ionic liquid is preferentially dissolved in this compartment. In this case, the osmotic pressure is higher than without any salts in the aqueous phases. However, the loss rate without any salts in the aqueous phases (78\%) is higher than the loss rate when one of the aqueous phase is composed of a concentrated sodium chloride solution (45\%). These observations are in accordance with the observations of Kemperman et al. [18], who considered that the osmotic pressure is not the main cause of degradation of SLMs made of molecular diluents.

A different behavior is observed for a liquid membrane composed of pure tri-butyl phosphate (figure 7). This organophosphorous molecule has a lower solubility in water (280 mg. $\left.\mathrm{L}^{-1},[44]\right)$ than most of the imidazolium ionic liquids, leading to a lower loss rate in pure water. Contrary to what happened for the ionic liquid, it seems that the salting-out effect appears at any concentrations of sodium chloride and reduces the membrane loss rate for pure TBP, as already mentioned for biphasic systems [45]. 


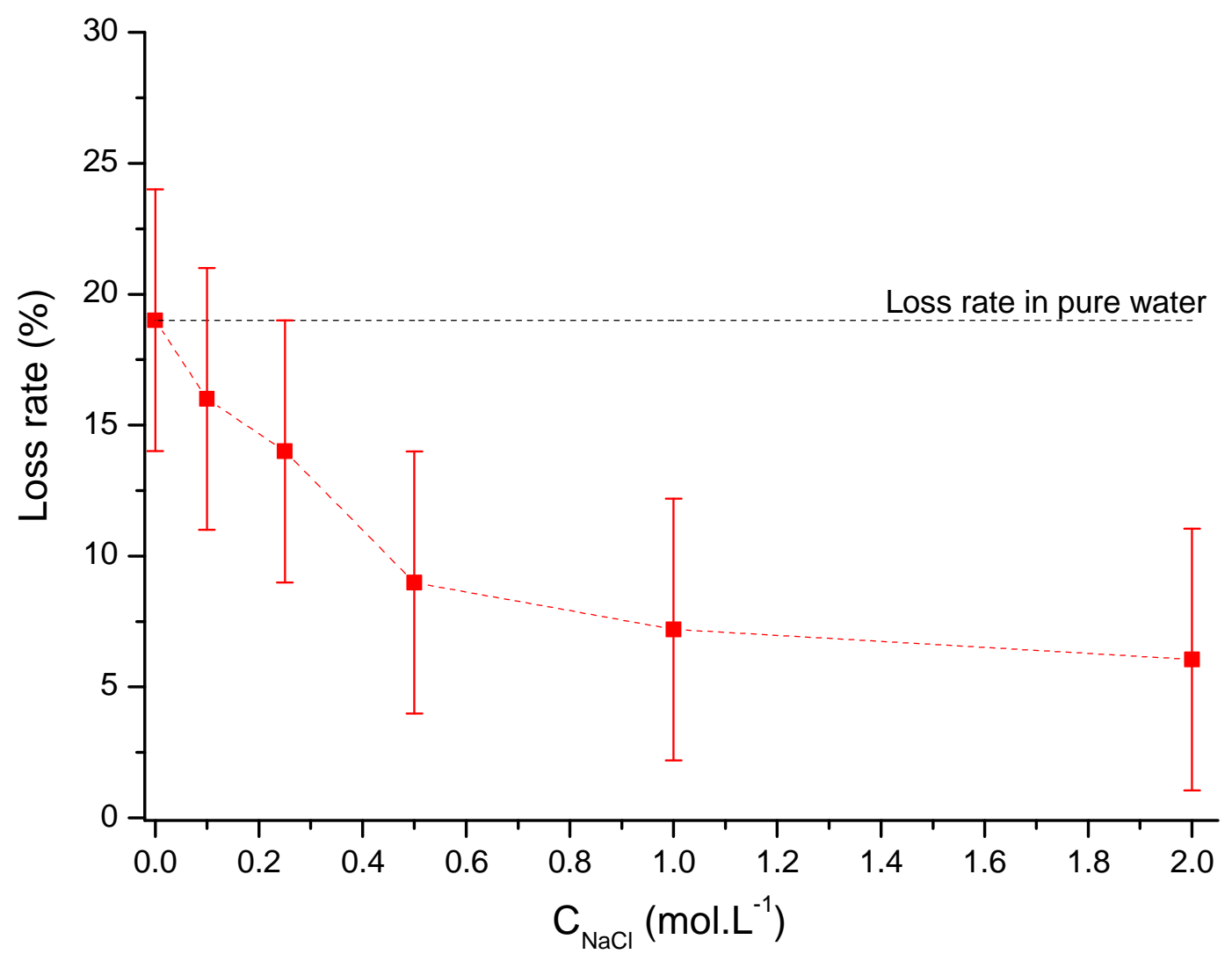

Figure 7. Membrane loss rate (\%) after one hour of contact with aqueous solutions of sodium chloride . Liquid membrane phase: TBP immersed in hydrophobic PVDF membranes. Dot horizontal line: loss rate in pure water. The lines are drawn for clarification purpose

It can be concluded that the addition of salts in the aqueous phases could be a solution to enhance the salting-out effect and favor the stability of the supported ionic liquid membrane. But the salting-out or salting-in effect and its magnitude are dependant of the constitution and concentration of the salt using ionic liquids. According to these results, highly concentrated aqueous solutions of sodium carbonate were used as a receiving (stripping) phase. This specie is considered as more kosmotrope than sulfate. Moreover, this salt is frequently used as a precipitating agent for lithium $[6,46]$, due to the lower solubility of lithium carbonate in these solutions when the temperature is increased.

Using these kinds of aqueous receiving solutions, the separation process can combine extraction, stripping and precipitation of the metal in one single step. Furthermore, the aqueous solubility of the ionic liquid is reduced at high concentrations of sodium carbonate in the aqueous phase due to its salting-out effect [42]. However, it is well known that the PVDF polymer can undergo hydrofluorination reactions in contact with basic solutions [4748], and this degradation can lead to a lower stability of the liquid membrane [49]. So, to decrease the $\mathrm{pH}$ of the receiving phase and to avoid the degradation of the membrane polymer, an equimolar mixture of sodium carbonate $\left(\mathrm{Na}_{2} \mathrm{CO}_{3}\right)$ and sodium hydrogen carbonate $\left(\mathrm{NaHCO}_{3}\right)$ was used as a receiving phase $\left(1 \mathrm{~mol} . \mathrm{L}^{-1} \mathrm{Na}_{2} \mathrm{CO}_{3}\right.$ and $\left.1 \mathrm{~mol} . \mathrm{L}^{-1} \mathrm{NaHCO}_{3}\right)$. 


\subsection{Lithium transport across a supported ionic liquid membrane}

\subsubsection{Lithium transport in $\mathrm{LiCl} / /(\mathrm{TBP}+\mathrm{IL}) / /\left(\mathrm{Na}_{2} \mathrm{CO}_{3}+\mathrm{NaHCO}_{3}\right) \mathrm{SLM}$ system}

The transport behavior of lithium ions through a SLM was studied with the use of the mixture of $\left[\mathrm{C}_{4} \mathrm{mim}\right]\left[\mathrm{NTf}_{2}\right]$ ionic liquid and TBP as a carrier. An aqueous feed phase was prepared by dissolving lithium chloride salt. The composition of the supported organic phase was defined based on the results of the lithium liquid-liquid extraction (i.e. in the biphasic extraction system) from aqueous solutions into organic phase containing different concentrations of TBP dissolved in imidazolium-based ionic liquids [27]. The mixture TBP-IL providing the highest distribution ratio values of lithium, namely $10 \% \mathrm{v} / \mathrm{v}\left[\mathrm{C}_{4} \mathrm{mim}\right]\left[\mathrm{NTf}_{2}\right]$ and $90 \% \mathrm{v} / \mathrm{v}$ TBP was used for all further experiments in present work. The ionic liquid cation has to be rather hydrophilic in order to undergo the exchange with the lithium ion [26]. This system is denoted as follows: $\mathrm{MA} / /(\mathrm{TBP}+\mathrm{IL}) / /\left(\mathrm{Na}_{2} \mathrm{CO}_{3}+\mathrm{NaHCO}_{3}\right)$, "MA" referring to the metals placed in the feed phase and their counter anions, (TBP+IL) referring to the liquid membrane phase and $\left(\mathrm{Na}_{2} \mathrm{CO}_{3}+\mathrm{NaHCO}_{3}\right)$ referring to the composition of the receiving phase. Lithium transport across a supported liquid membrane containing TBP and $\left[\mathrm{C}_{4} \mathrm{mim}\right]\left[\mathrm{NTf}_{2}\right]$ mixture is shown in figure 8 . As can be seen, lithium ions are extracted from the feed phase and simultaneously released in the receiving phase. The lithium transport is stopped after 55 hours providing $65 \%$ transportation level of lithium.

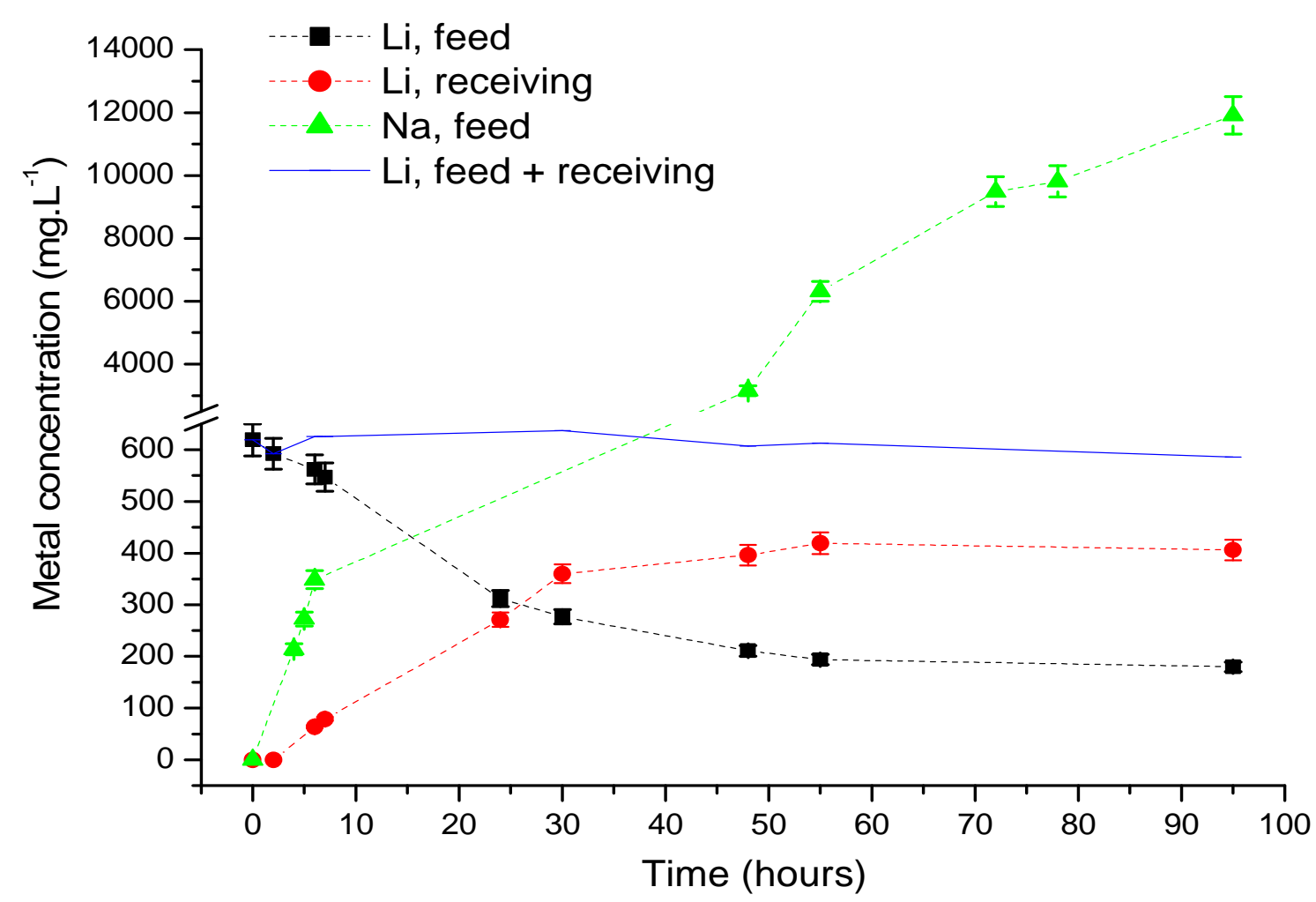

Figure 8. Evolution of lithium concentration in the feed and receiving phase, and sodium concentration in feed phase as a function of time during IL-based SLM operation. Y axis: Break between 650 and $2500 \mathrm{mg} / \mathrm{L}$. The lines are drawn for clarification purposes. Feed phase composition: LiCl $619 \mathrm{mg} . \mathrm{L}^{-1}$; Receiving phase composition: $\mathrm{Na}_{2} \mathrm{CO}_{3} / \mathrm{NaHCO}_{3}\left(1 \mathrm{~mol} . \mathrm{L}^{-1} / 1 \mathrm{~mol} . \mathrm{L}^{-1}\right)$ 
Mass balance which is stated as a control for the quality of experiments is well checked over the run. On the other side, sodium is transported from the receiving to the feed phase even after 55 hours, leading to a large increase of sodium concentration in the feed phase.

The membrane stability is noteworthy during the first two days of use allowing a stable lithium flux, even with the high osmotic pressure imposed across the membrane under experimental conditions used. The UV-vis spectra are recorded in the feed solution to follow the behavior of the ionic liquid. The absorbance at $211 \mathrm{~nm}$ is reported in table 3 at several time intervals. The absorbance related to the imidazolium cation is gradually increasing, thus indicating that the ionic liquid initially in the liquid membrane is progressively dissolved. The dissolution of the ionic liquid could be a cause of the interruption of the transport observed after two days of use.

Table 3.

Absorbance at $211 \mathrm{~nm}$ in both compartments at several time intervals. See figure 8 for the composition of the liquid membrane and of the aqueous phases.

\begin{tabular}{cc}
\hline Time & Absorbance at $\lambda=211 \mathrm{~nm}$ \\
\hline 0 & 0 \\
\hline 2 hours & 0.07 \\
\hline 8 hours & 0.12 \\
\hline 24 hours & 0.51 \\
\hline 30 hours & 0.60 \\
\hline
\end{tabular}

\subsubsection{Lithium transport in $(\mathrm{LiCl}+\mathrm{NaCl}) / /(\mathrm{TBP}+\mathrm{IL}) / /\left(\mathrm{Na}_{2} \mathrm{CO}_{3}+\mathrm{NaHCO}_{3}\right)$}

The natural sources of lithium often contain large amounts of sodium chloride such as brines [50], geothermal waters [5], or seawater [51]. In these cases, the separation of lithium from sodium is needed. According to the results obtained in $\mathrm{LiCl} / /(\mathrm{TBP}+\mathrm{IL}) / /\left(\mathrm{Na}_{2} \mathrm{CO}_{3}+\mathrm{NaHCO}_{3}\right)$ SLM system, the high chemical potential of sodium in the receiving phase leads to its transport from the receiving phase to the feed one. In figure 9, lithium and sodium concentrations are reported in the feed and receiving phase over time. 


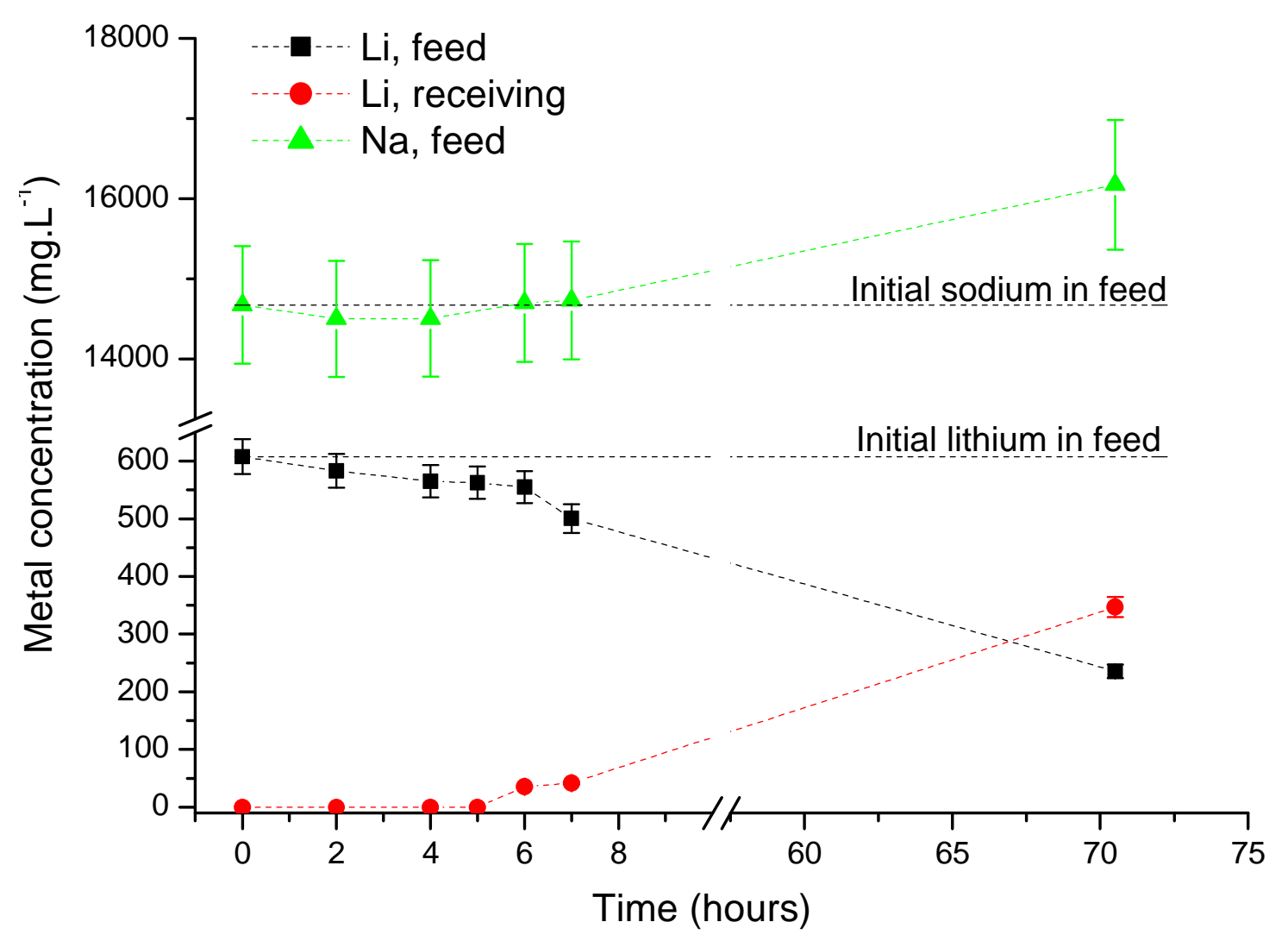

Figure 9. Evolution of lithium concentration in the feed and receiving phase; Evolution of sodium concentration in feed (filled triangle) over time. Y axis: break between 650 and $13000 \mathrm{mg} / \mathrm{L}$. X axis: break between 10 and 55 hours. The lines are drawn for clarification purposes. Feed phase composition: $\mathrm{LiCl} 608 \mathrm{mg} \cdot \mathrm{L}^{-1}+\mathrm{NaCl} 15,2 \mathrm{~g} \cdot \mathrm{L}^{-1}$; Receiving phase composition: $\mathrm{Na}_{2} \mathrm{CO}_{3} / \mathrm{NaHCO}_{3}\left(1 \mathrm{~mol} \cdot \mathrm{L}^{-1} / 1 \mathrm{~mol} . \mathrm{L}^{-1}\right)$

Lithium is still transported from the feed to the receiving phase, while sodium is transported from the receiving phase to the feed phase, even if the initial feed solution contains large amounts of sodium chloride as compared to the lithium content. It can be seen that the sodium content in the feed phase is increased after several hours of SLM process, while the lithium content is decreased, leading to an efficient separation of lithium in the feed from its initial sodium chloride content.

\subsubsection{Lithium separation in ( $\left.\mathrm{LiCl}+\mathrm{MgCl}_{2}\right) / /(\mathrm{TBP}+\mathrm{IL}) / /\left(\mathrm{Na}_{2} \mathrm{CO}_{3}+\mathrm{NaHCO}_{3}\right)$}

More than sodium, the separation of lithium from magnesium is of primary importance and remains challenging due to the similar chemical behavior of these two cations. Figure 10 shows the evolution of lithium and magnesium concentrations over time in the feed and receiving phases. 


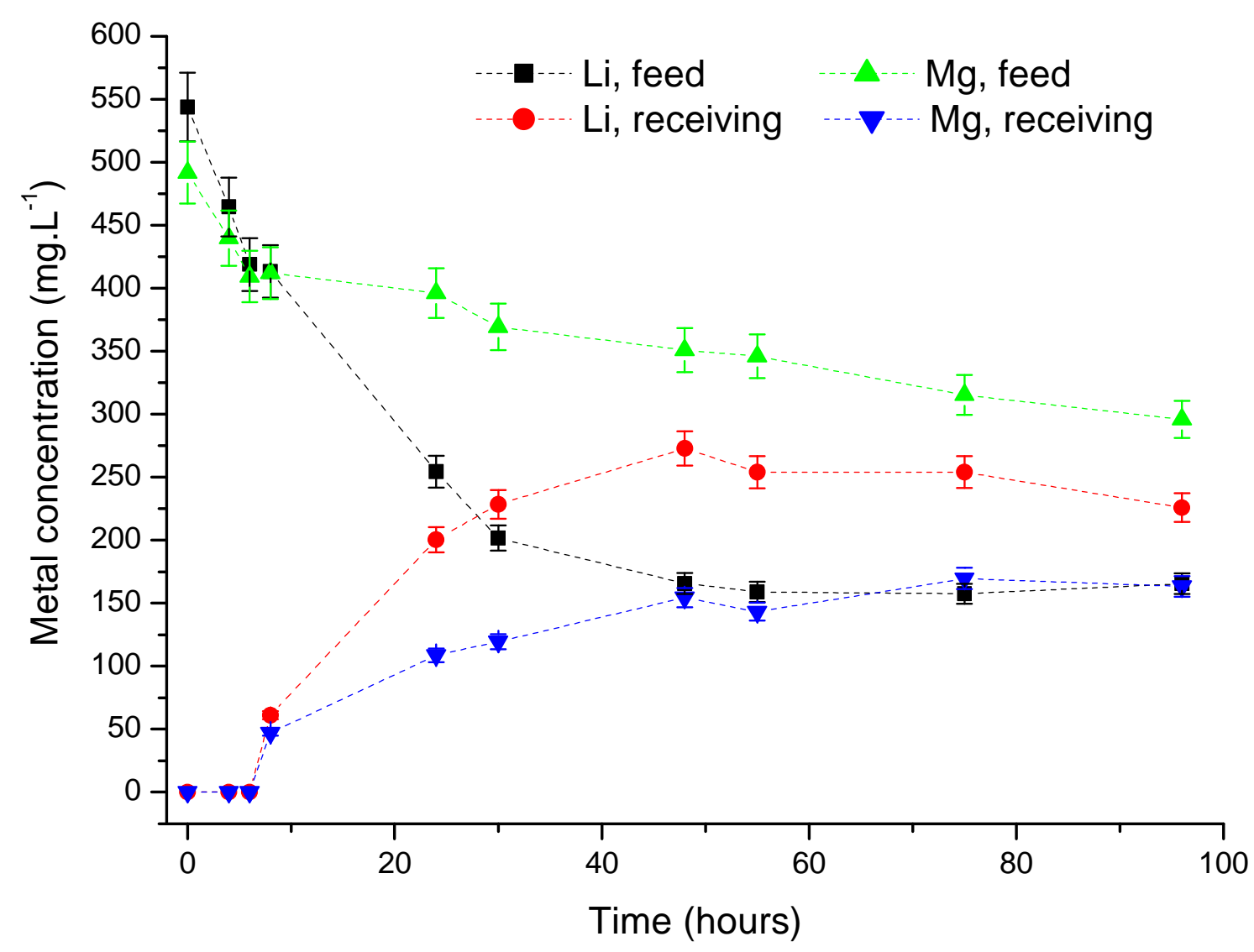

Figure 10. Evolution of lithium and magnesium concentrations in the feed and receiving phases over time. The lines are drawn for clarification purposes. Feed phase composition: $\mathrm{LiCl} 544 \mathrm{mg} \cdot \mathrm{L}^{-1}+\mathrm{MgCl}_{2} 492 \mathrm{mg} \cdot \mathrm{L}^{-1}$; Receiving phase composition: $\mathrm{Na}_{2} \mathrm{CO}_{3} / \mathrm{NaHCO}_{3}\left(1 \mathrm{~mol} . \mathrm{L}^{-1} / 1 \mathrm{~mol} . \mathrm{L}^{-1}\right)$

In the first hours of the experiment, it can be seen that lithium and magnesium concentrations in the feed phase are decreasing. The decrease in lithium concentration is slightly faster than magnesium. But after more than ten hours of transport, it can be seen that lithium concentration is still decreasing at the same rate, while magnesium is slightly extracted from the feed phase. This could be related to the ionic liquid content in the liquid membrane. In the first few hours, more ionic liquid is available at the feed/liquid membrane interface, leading to an efficient extraction of both metals. However, when the ionic liquid content is lower due to its exchange and dissolution, the lithium extraction is favorised. These variations can affect the efficiency of the separation between the two metals, as observed in figure 10. However, after 75 hours of transport, it can be seen lithium is back transported from the receiving phase to the feed phase, leading to a decrease in the metal content in the receiving phase.

\subsubsection{Lithium separation in $\left(\mathrm{Li}_{2} \mathrm{SO}_{4}+\mathrm{COSO}_{4}+\mathrm{NiSO} \mathrm{O}_{4}\right) / /(\mathrm{TBP}+\mathrm{IL}) / /\left(\mathrm{Na}_{2} \mathrm{CO}_{3}+\mathrm{NaHCO} \mathrm{O}_{3}\right) \mathrm{SLM}$ system}

On the other side, the separation of lithium from cobalt and nickel is one of the challenges for the recycling of spent lithium-ion batteries [52-53]. After the leaching step, these metals are in solution and must be separated. The leaching step can be made using several mineral [54] or organic acids [55]. But the use of sulfuric acid is of advantage, this acid being less corrosive than other mineral acids [56]. The initial feed solution contains cobalt(II), nickel(II) and lithium(l) as their metal sulfates, at an initial pH lower than $1\left(\mathrm{H}_{2} \mathrm{SO}_{4}\right)$. The evolution of 
theses metal's concentrations over time in the feed and receiving phase are shown in figure 11.

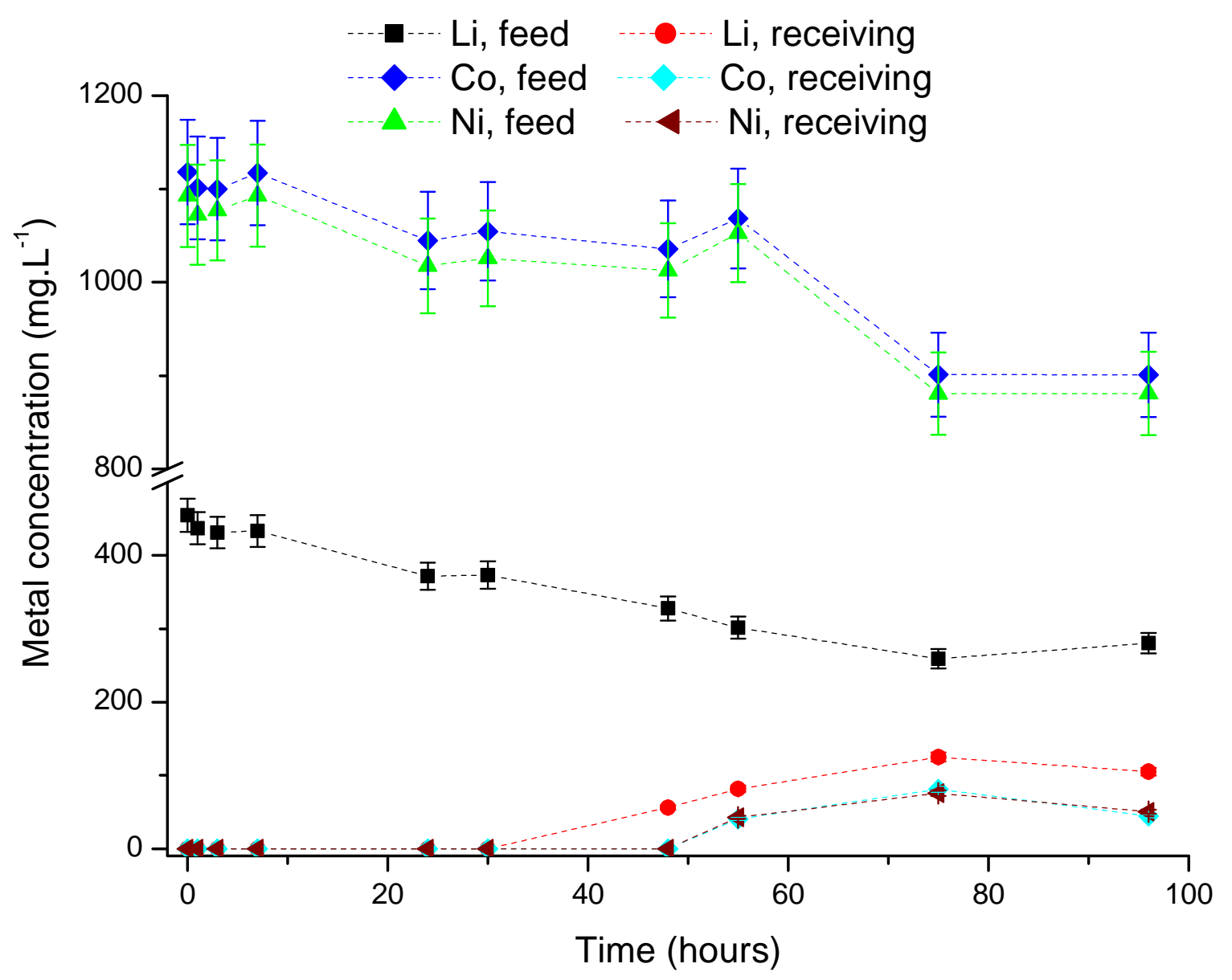

Figure 11. Evolution of lithium, cobalt and nickel concentrations in the feed and receiving phases over time. $Y$ axis: break between 500 and $800 \mathrm{mg} / \mathrm{L}$. The lines are drawn for clarification purposes. Feed phase composition: $\mathrm{Li}_{2} \mathrm{SO}_{4} 455 \mathrm{mg} \cdot \mathrm{L}^{-1}+\mathrm{CoSO}_{4} 1,12 \mathrm{~g} \cdot \mathrm{L}^{-1}+\mathrm{NiSO}_{4} 1,09 \mathrm{~g} \cdot \mathrm{L}^{-1}+\mathrm{H}_{2} \mathrm{SO}_{4}$ 0,1 mol.L $\mathrm{L}^{-1}$; Receiving phase composition: $\mathrm{Na}_{2} \mathrm{CO}_{3} / \mathrm{NaHCO}_{3}\left(1 \mathrm{~mol} . \mathrm{L}^{-1} / 1 \mathrm{~mol} . \mathrm{L}^{-1}\right)$

Different behaviors are observed for these metals. It can be seen that the lithium content in the feed phase decreases as soon as the experiments starts. The nickel and cobalt content in the feed phase stays almost constant in the first hours of the experiments. Between 20 and 48 hours of experiment, the cobalt and nickel content diminish minorly, while lithium concentration is constantly decreasing. However, after 60 hours it can be seen those cobalt and nickel concentrations have decreased abruptly. These different behaviors could be related to the transport of protons from the acidic feed phase to the receiving phase, as evidenced by the evolution of the $\mathrm{pH}$ in these aqueous phases (figure 12). 


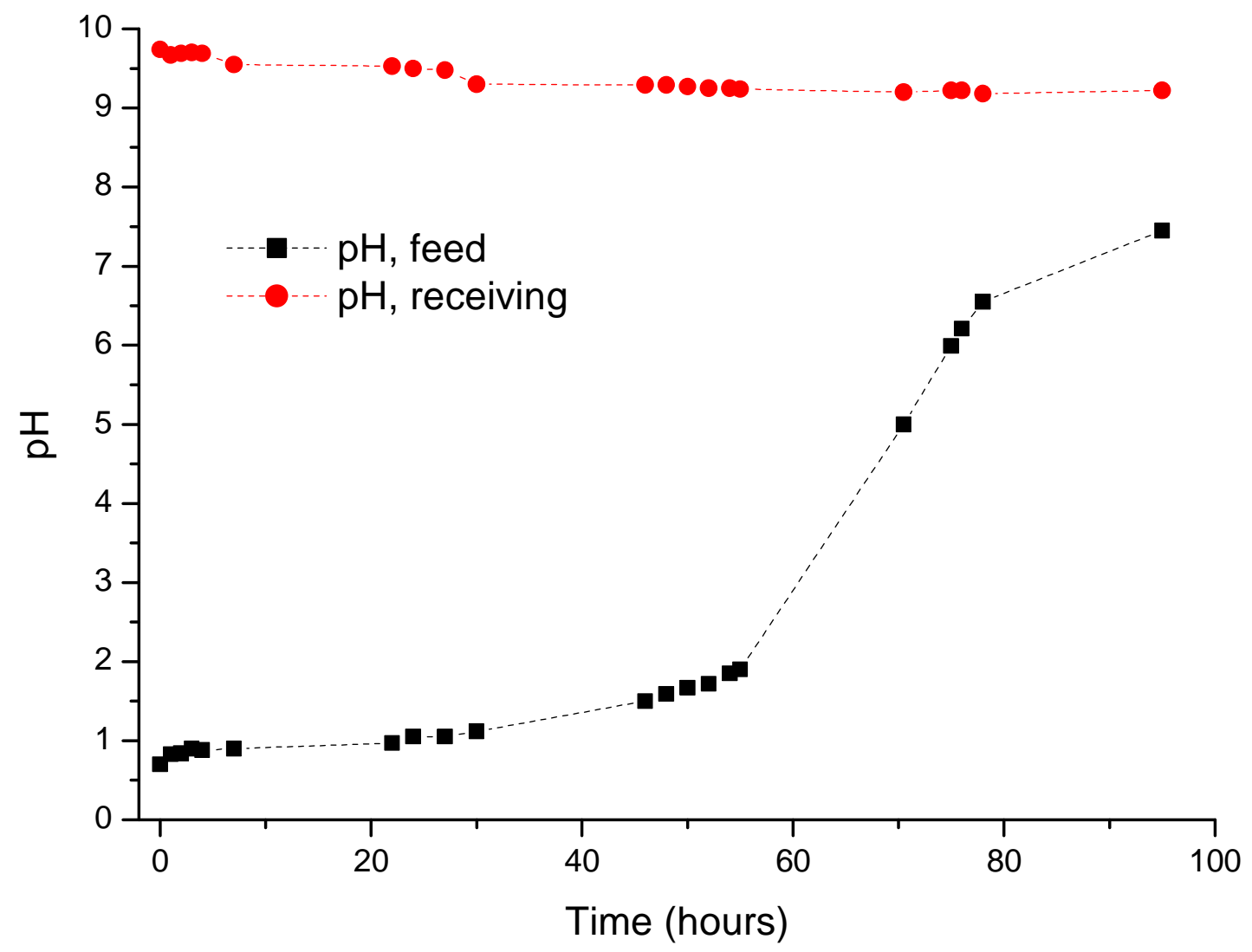

Figure 12. Evolution of the $\mathrm{pH}$ of the aqueous feed (black square) and aqueous receiving (red dot) phases. The lines are drawn for clarification purpose. Composition of the aqueous phases: see figure 12.

During the first hours of the experiment, protons and lithium are co-transported across the liquid membrane, leading to an increase of the feed phase $\mathrm{pH}$ and to a decrease of the lithium concentration. The saturation of the liquid membrane/feed phase interface with protons and lithium and the better affinity of tri-butyl phosphate for these two ions under acidic conditions can explain the low extraction of cobalt and nickel at the start of the experiments. After 60 hours the $\mathrm{pH}$ is still increasing, reaching near neutral values. As soon as the $\mathrm{pH}$ is higher than 1.5 the nickel and cobalt extraction prevails, leading to the transport of these two ions.

The transport of protons could be a way to promote lithium co-transport while leaving the other metal ions in the feed phase and leading to a high selectivity for lithium over the transition metals. Moreover, using imidazolium ionic liquids associated to tri-butyl phosphate in liquid-liquid extraction systems, an increase of the acidity of the aqueous phase leads to a large decrease in the extraction efficiency of lithium [26-27]. Using this liquid membrane system, extraction of lithium is possible even from acidic solutions.

Starting from an initial feed solution containing larger amounts of cobalt and nickel than lithium, it can be seen that the receiving phase contains more lithium than cobalt and nickel after 75 hours of transport. However, the amount of metals recovered in the receiving phase is lower than the amounts of metals extracted from the feed phase. This could be related to two different effects already mentioned with supported ionic liquid membranes [58]: the metals are not released in the receiving phase, or the metals are precipitating under their carbonate or hydroxide form, under the basic conditions prevailing in the receiving phase. It 
can also be seen that between 75 and 96 hours, the metals' content in the receiving phase have decreased. The metals are back transported to the feed phase during this period.

\subsubsection{Comparison of the permeation coefficients}

A comparison of the permeation coefficients of lithium obtained in the experiments above mentioned is shown in Table 4. The permeation coefficients are calculated on the first 24 hours of transport, in which the liquid membrane has provided a stable lithium flux.

Table 4.

Permeation coefficients obtained with different composition of the feed phase

\begin{tabular}{ccc}
\hline Composition of the initial feed phase & $\begin{array}{c}\text { Metal concentration in the } \\
\text { initial feed phase }\end{array}$ & $\begin{array}{c}\mathrm{P}\left(\mathrm{Li}^{+}\right) \text {after 24 hours of } \\
\text { transport }\left(\mathrm{cm} . \mathrm{s}^{-1}\right)\end{array}$ \\
\hline $\mathrm{LiCl}$ & {$\left[\mathrm{Li}^{+}\right]=619 \mathrm{mg} \cdot \mathrm{L}^{-1}$} & $1.2 \times 10^{-4}$ \\
\hline $\mathrm{LiCl}+\mathrm{NaCl}$ & $\begin{array}{c}{\left[\mathrm{Li}^{+}\right]=608 \mathrm{mg} \cdot \mathrm{L}^{-1}} \\
{\left[\mathrm{Na}{ }^{+}\right]=15,2 \mathrm{~g} \cdot \mathrm{L}^{-1}}\end{array}$ & $8.7 \times 10^{-5}$ \\
\hline $\mathrm{LiCl}+\mathrm{MgCl}_{2}$ & $\begin{array}{c}{\left[\mathrm{Li}^{+}\right]=544 \mathrm{mg} \cdot \mathrm{L}^{-1}} \\
{\left[\mathrm{Mg}^{2+}\right]=492 \mathrm{mg} \cdot \mathrm{L}^{-1}}\end{array}$ & $1.1 \times 10^{-4}$ \\
\hline $\mathrm{Li}_{2} \mathrm{SO}_{4}+\mathrm{CoSO}_{4}+\mathrm{NiSO}_{4}$ & $\begin{array}{l}{\left[\mathrm{Li}^{+}\right]=455 \mathrm{mg} \cdot \mathrm{L}^{-1}} \\
{\left[\mathrm{Co}^{2+}\right]=1,12 \mathrm{~g} \cdot \mathrm{L}^{-1}}\end{array}$ & $3.0 \times 10^{-5}$ \\
{$\left[\mathrm{Ni}^{2+}\right]=1,09 \mathrm{~g} \cdot \mathrm{L}^{-1}$} & \\
\hline
\end{tabular}

Despite the high concentrations of lithium used in the feed phase at the start of these experiments, it can be seen that the permeation coefficients remain elevated $\left(P \approx 10^{-4} \mathrm{~cm} . \mathrm{s}^{-1}\right)$ and comparable to those obtained for several metals using liquid membranes [17]. However, in the case of the lithium, cobalt and nickel competitive transport in sulfuric media, the permeation coefficient is lower. The saturation of the liquid membrane interface with protons could be a reason of this lowering. The performances obtained in terms of flux, permeation and stability are shown in table 5 and compared with supported liquid membranes based on molecular diluents. 
Table 5.

Comparison of flux, permeation and stability obtained in the literature for lithium extraction using supported liquid membranes

\begin{tabular}{|c|c|c|c|c|}
\hline Liquid membrane & $\begin{array}{l}\text { Lithium } \\
\text { flux }(\mathrm{J})\end{array}$ & $\begin{array}{l}\text { Lithium } \\
\text { permeation } \\
\text { coefficient }(\mathrm{P})\end{array}$ & $\begin{array}{l}\text { Membrane } \\
\text { stability }\end{array}$ & Reference \\
\hline $\begin{array}{c}{\left[\mathrm{C}_{4} \mathrm{mim}\right]\left[\mathrm{NTf}_{2}\right] \text { ionic liquid }} \\
\text { dissolved in TBP }\end{array}$ & $\begin{array}{l}\text { Up to } 7 \times 10^{-7} \\
\text { mol.cm }{ }^{2} \cdot \mathrm{s}^{-1}\end{array}$ & $\begin{array}{c}\text { Up to } 12 \times 10^{-7} \\
\mathrm{~m} \cdot \mathrm{s}^{-1}\end{array}$ & 2 days & This work \\
\hline $\begin{array}{l}\alpha \text {-acetylm- } \\
\text { dodecylacetophenone and } \\
\text { tri-octyl phosphine oxide } \\
\text { dissolved in kerosene }\end{array}$ & - & $\begin{array}{l}\text { Up to } 20 \times 10^{-7} \\
\mathrm{~m} \cdot \mathrm{s}^{-1}\end{array}$ & 3 days & [8] \\
\hline $\begin{array}{l}\text { di-2-ethyl hexyl phosphoric } \\
\text { acid and TBP dissolved in } \\
\text { kerosene }\end{array}$ & $\begin{array}{l}1.41 \times 10^{-6} \\
\mathrm{~mol} . \mathrm{cm}^{2} \cdot \mathrm{s}^{-1}\end{array}$ & - & Not reported & [23] \\
\hline
\end{tabular}

As compared to the results obtained with liquid membranes based on molecular diluents, the results obtained in this study are quite similar for the lithium extraction performances (permeation coefficients and lithium flux). But the extraction of lithium with conventional liquid membranes is only possible under basic conditions in the aqueous feed phase. Concerning membrane stability, Ma et al. have reported flux drops after 3 days of use. In our case, the stability is limited to two days by the progressive exchange and dissolution of the ionic liquid to the aqueous phases.

\subsection{Description of transport and role of the ionic liquid}

\subsubsection{Influence of the carrier/ionic liquid ratio in the facilitated transport of lithium}

The influence of the organic phase composition, i.e. carrier/ionic liquid ratio in the supported liquid membrane, on the lithium permeability has been studied. The plot of permeability values $\ln \frac{C_{f, t}}{C_{f, 0}}$ of lithium for various proportions of TBP and $\left[\mathrm{C}_{4} \mathrm{mim}\right]\left[\mathrm{Tf}_{2} \mathrm{~N}\right]$ ionic liquid in the SILM versus time is reported in Figure 13. 


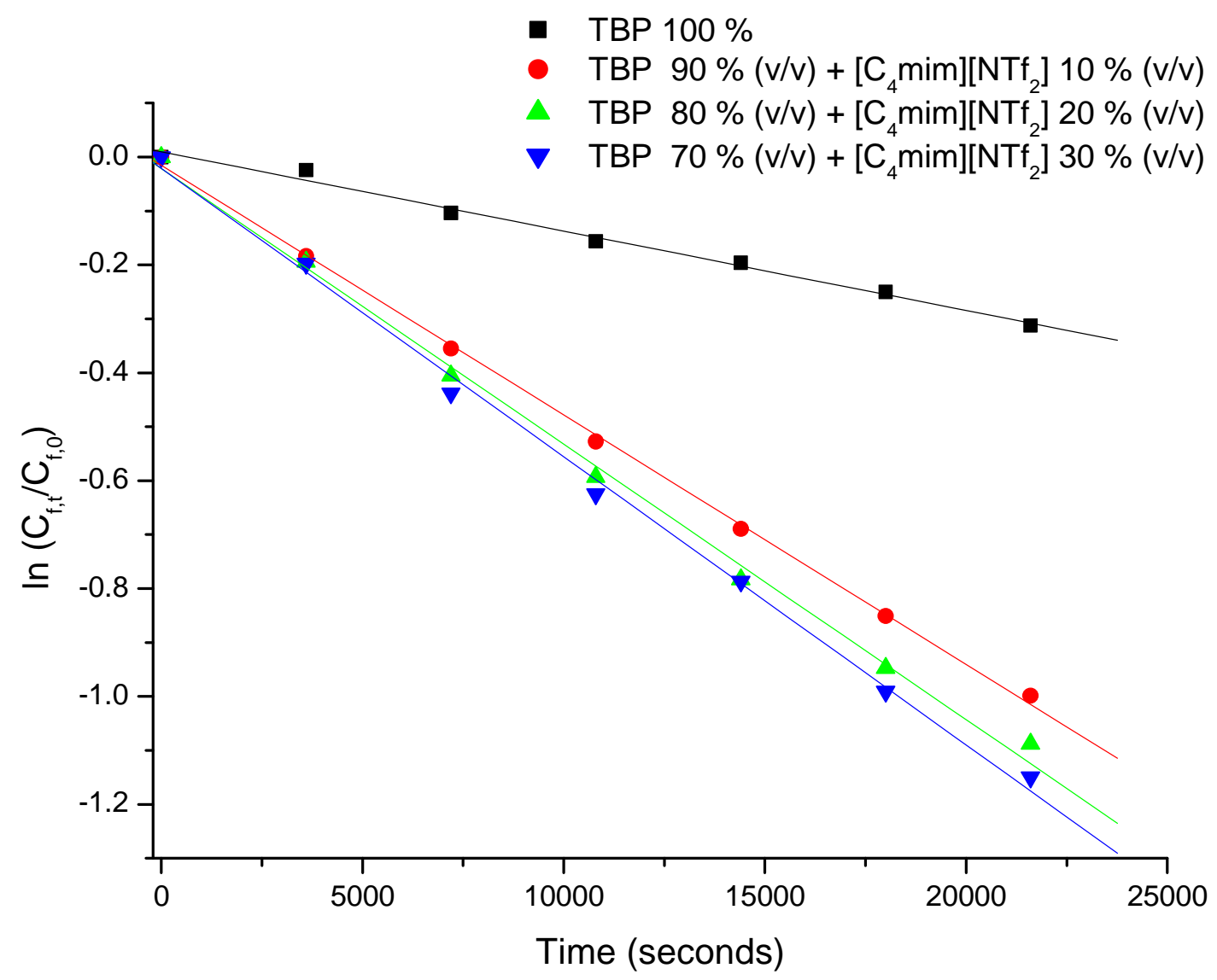

Figure 13. Plot of $\ln \left(\mathrm{C}_{\mathrm{f}, \mathrm{t}} / \mathrm{C}_{\mathrm{f}, 0}\right)$ versus time for various proportions of TBP and $\left[\mathrm{C}_{4} \mathrm{mim}\right]\left[\mathrm{NTf} \mathrm{f}_{2}\right]$ in the SILM Feed phase composition: $[\mathrm{LiCl}]=5 \mathrm{mg} \cdot \mathrm{L}^{-1}$; Receiving phase composition: $\left[\mathrm{Na}_{2} \mathrm{CO}_{3}\right] /\left[\mathrm{NaHCO}_{3}\right]=\left[1 \mathrm{~mol} \cdot \mathrm{L}^{-1}\right] /\left[1 \mathrm{~mol} \cdot \mathrm{L}^{-1}\right]$.

The metal ions transport through a polymeric support, i.e. through non-impregnated membrane film, is null, due to the high hydrophobicity of the PVDF polymer [58]. However, from the data in Figure 13, it is apparent that the supported liquid membrane with only TBP allows the transport of lithium ions and permeability coefficient values increase as the ionic liquid content increases. It is evident that TBP acts as a carrier in the SLM, i.e. it is responsible of the transport of the lithium ion. Facilitated transport occurs, involving the exchange of the metal ions with the ionic liquid cation. But due to the solubility of metals into pure TBP, simple permeation is occurring too. In simple permeation, the transported substance dissolves into the organic liquid membrane and diffuses to the receiving phase. In this case, the difference of chemical potential is the only driving force, and the transport stops as soon as the equilibrium is reached. The difference of chemical potential can be written as follows (Eq. (5)) [59] :

$$
\mathrm{d} \mu_{i}=\mathrm{RT} \operatorname{dln} C_{i}+R T d \ln \gamma_{i}
$$

where $\mathrm{d} \mu_{i}$ is the difference of the chemical potential of metal (i) between the feed and receiving phases, $C_{i}$ being the concentration of the metal (i) in the aqueous phases, $\gamma_{i}$ the activity coefficient of the metal and $R$ being the universal gas constant. Temperature (T) in the aqueous phase is constant in our conditions. 
Considering an activity coefficient equal to one in both aqueous phases, the concentration profile of a SLM composed of pure TBP is displayed in Figure 14 (a). In facilitated transport, a metal-carrier complex is formed at the feed/liquid membrane interface, creating a permanent concentration gradient through the membrane, which allows the enrichment of the transported substance in the receiving phase. But the affinity of pure TBP for the alkali metal cations being low, the concentration gradient created through the liquid membrane is low. The transport of metal cations across a liquid membrane composed of pure TBP will be closer to simple permeation rather than to facilitated transport. Moreover, the receiving phase is composed of a concentrated electrolyte while the feed phase is made of the diluted metal in water, leading to major differences in the activity coefficients of metals in the two aqueous phases. The activity coefficient of water is lower in aqueous sodium carbonate solutions [60], thus increasing the activity coefficients of metals in it. The activity profile across a liquid membrane made of pure TBP is shown in figure 14 (b), when the receiving phase is a concentrated aqueous electrolyte. The differences in activity coefficients between the feed and receiving solutions will result on a large increase in lithium activity at the liquid membrane/receiving phase interface, implicating that the equilibrium of chemical potentials will be reached fastly. The effect of the chemical potential differences can be seen in Figure 9 and 10. As long as the chemical potential of sodium is higher in the receiving phase, sodium is transported to the feed phase.

When adding $\left[\mathrm{C}_{4} \mathrm{mim}\right]\left[\mathrm{NTf}_{2}\right]$ ionic liquid in the supported liquid membrane, Figure 13 shows that the permeation of the lithium ions is higher. It could be due to a larger amount of the ionic liquid cation available at the interface of the liquid membrane to undergo the exchange with the lithium ion. The activity profile of a liquid membrane composed of TBP and the $\left[\mathrm{C}_{4} \mathrm{mim}\right]\left[\mathrm{NTf}_{2}\right]$ ionic liquid is proposed in figure 14 (c). The exchange of the lithium ion with the ionic liquid cation enhances the activity gradient created across the liquid membrane, allowing to increase the driving force. When using liquid-liquid extraction, the extraction efficiency of the lithium ion is low when using pure TBP ( $\approx 8 \%)$, but can reach values up to 80 $\%$ when adding $\left[\mathrm{C}_{4} \mathrm{mim}\right]\left[\mathrm{NTf}_{2}\right]$ in the organic phase [27]. This effect leads to a large increase in the amount of lithium recovered in the receiving phase, despite the unfavorable activity coefficient bias between both sides.

But as soon as the ionic liquid is entirely dissolved in the surrounding aqueous phases, there is only pure TBP left in the liquid membrane. In this situation, due to the high activity of metals in the receiving phase, it can be seen in figure 10 and 11 that lithium can be backtransported from the receiving phase to the feed phase. The presence of the ionic liquid cation is of advantage to obtain a facilitated transport in this configuration. But the dissolution and exchange of the ionic liquid cation appears to be the main limitation of this system.

\subsubsection{Influence of the ionic liquid anion in the liquid membrane}

It can also be noticed from Table 3 that lithium transport is possible whatever the counteranion present in the aqueous phase. The works of Izzat and co-workers [61-62] have outlined the role of the counter anion in the rate of transport of metals across liquid membranes, using macrocyclic neutral ligands. Their works have shown that the rate of transport is highly dependent on the counter-anion when using electrically neutral carriers, 
since the transport of the cation and its counter-anion is needed to maintain the electrical neutrality in the liquid membrane phase [63]. This is also true for the neutral (or solvation) carrier tri-butyl phosphate, for which only the transport of neutral species has been reported [23-25]. Considering that the transport of electrically neutral species is needed, and that no major differences in lithium transport are observed even with two hydrophilic counteranions such as chlorides and sulfates, it seems that the ionic liquid anions $\mathrm{NTf}_{2}{ }^{-}$play a key role in this SILM system, allowing the formation and transport of more hydrophobic lithiumTBP- $\mathrm{Tf}_{2} \mathrm{~N}$ complexes.

To conclude, the use of ionic liquids in the liquid membrane is essential to maintain the electrical neutrality of the species transported as well as to obtain an efficient facilitated transport. However, the exchange and the progressive dissolution of the ionic liquid cation is the main limitation of this system, leading to a decrease of the extraction performances after more than two days of continual use. Re-impregnation of the support with the ionic liquid could be a way to obtain a longer lifetime.

(a)

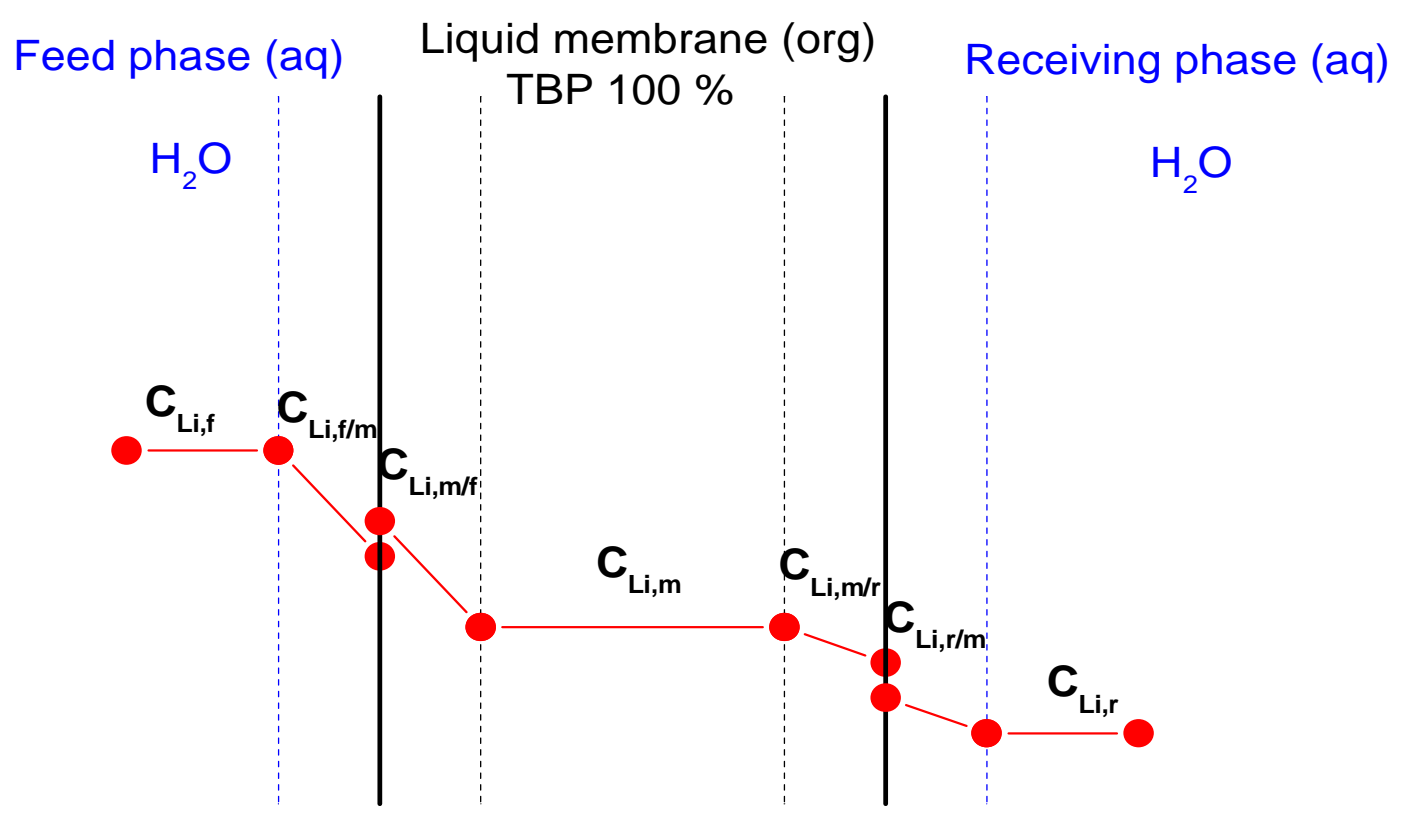


(b)

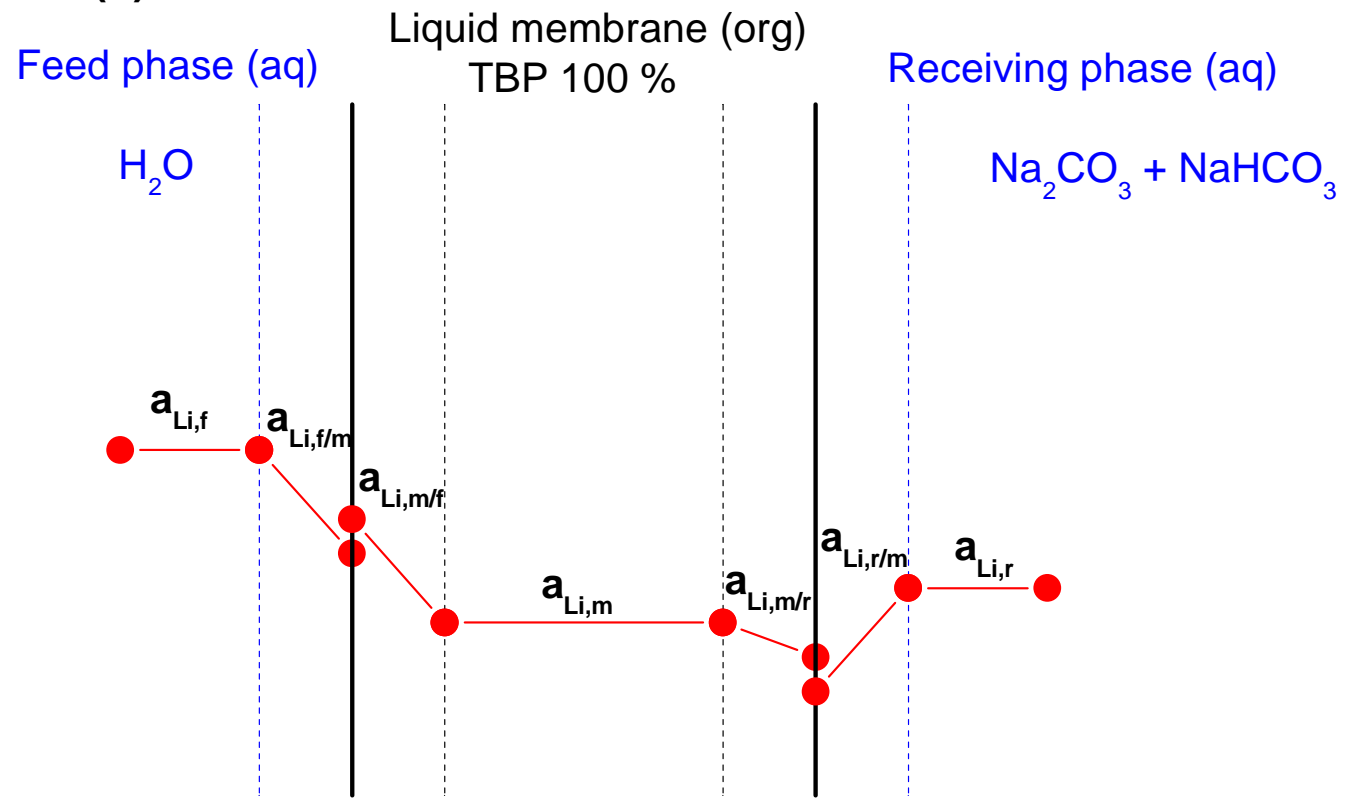

(c) Liquid membrane (org)

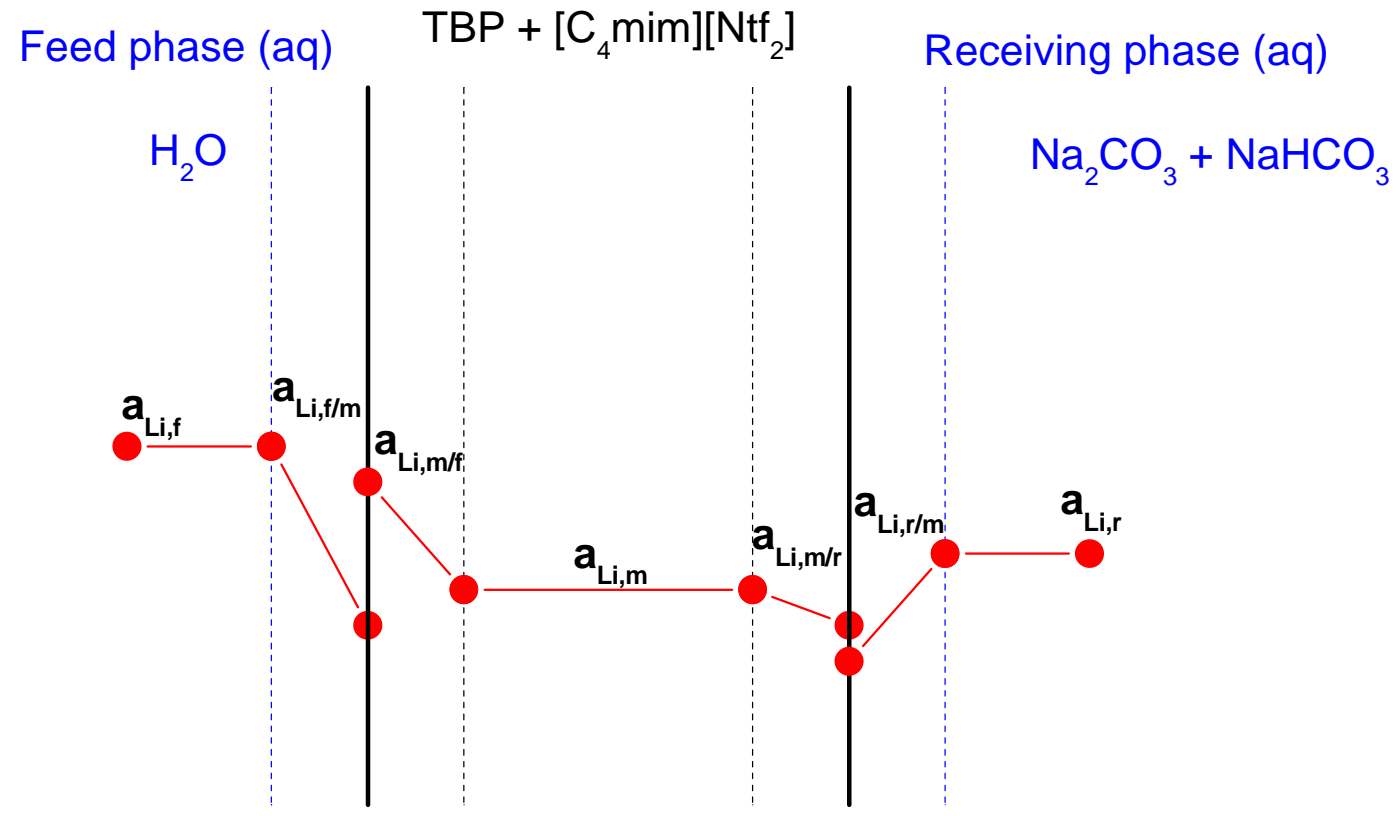

Figure 14. (a) : concentration profile across a liquid membrane made of pure TBP between two aqueous phase. $\mathrm{C}_{\mathrm{Li}}$ : concentration of lithium, " $\mathrm{f}$ " in the feed phase; " $\mathrm{f} / \mathrm{m}$ " in the aqueous boundary layer between the feed and the liquid membrane; " $m / f$ " in the liquid membrane at the interface with the feed phase; " $m$ " in the liquid membrane; " $\mathrm{m} / \mathrm{r}$ " in the liquid membrane at the interface with the receiving phase; " $\mathrm{r} / \mathrm{m}$ " in the aqueous boundary layer between the receiving phase and the liquid membrane, " $r$ " in the receiving phase

(b) activity profile across a liquid membrane of pure TBP between an aqueous feed phase and a receiving phase containing concentrated sodium carbonate and sodium hydrogen carbonate. $a_{\mathrm{L} i}$ being the activity of the lithium ion

(c) activity profile across a liquid membrane of TBP and $\left[\mathrm{C}_{4} \mathrm{mim}\right]\left[\mathrm{Ntf}_{2}\right]$ between an aqueous feed phase and a receiving phase containing concentrated sodium carbonate and sodium hydrogen carbonate 


\section{Conclusions}

The impregnation and stability of supported liquid membranes based on various hydrophobic ionic liquids has been studied. The mass of ionic liquid phase immobilized into the hydrophobic polymeric support is related to the ionic liquid density. Membrane stability seems to be highly correlated to the solubility of the organic phase in the surrounding aqueous phases. The addition of a salt that promotes the salting out effect could be a solution to improve membrane stability. Using a supported liquid membrane containing a mixture of tri- $n$-butylphosphate and imidazolium ionic liquid, lithium extraction and separation from complex aqueous media is possible even from acidic solutions. Using aqueous sodium carbonate solution as a receiving phase, the process can combine extraction, stripping and precipitation of the metal in a single step, with very low volumes of organic chemicals. The separation of lithium from sodium chloride can be done with this supported liquid membrane system. Promising results have been obtained for the separation of lithium from magnesium, cobalt and nickel. The use of ionic liquids in the liquid membrane is essential to maintain the electrical neutrality of the species transported as well as to obtain an efficient facilitated transport. However, the exchange and the progressive dissolution of the ionic liquid cation reduce the lifetime of the process.

\section{Acknowledgments}

The financial support from the French Environment \& Energy Management Agency (Agence de l'Environnement et de la Maîtrise de l'Énergie, ADEME, PhD fellowship to GZ) is gratefully acknowledged. The authors thank Dr A. Boos, P. Ronot and I. El-Masoudi (IPHC, France) for the ICP-OES analysis.

\section{References}

[1] G. Martin, L. Rentsch, M. Höck, M. Bertan, Lithium market research- global supply, future demand and price development, Energy Storage Materials 6 (2017) 171-179.

[2] P. W. Gruber, P.A. Medina, G.A. Keoleian, S.E. Kesler, M.P. Everson, T.J. Wallington, Global lithium availability: a constraint for electric vehicles?, J. Ind. Ecol. 15 (2011) 765-775.

[3] J.W. An, D.J. Kang, K.T. Tran, M.J. Kim, T. Lim, T. Tram, Recovery of lithium from Uyuni salar brine, Hydrometallurgy 117-118 (2012) 64-70

[4] L.I. Barbosa, G. Valente, R.P. Orosco, J.A. González, Lithium extraction from $\beta$-spodumene through chlorination with chlorine gas, Miner. Eng. 56 (2014) 29-34.

[5] T. Hano, M. Matsumoto, T. Ohtake, N. Egashir, F. Hori, Recovery of lithium from geothermal water by solvent extraction technique, Solvent Extr. Ion Exch. 10 (1992) 195-206.

[6] P. Zhang, T. Yokoyama, O. Itabashi, T.M. Suzuki, K. Inoue, Hydrometallurgical process for recovery of metal value from spent lithium-ion secondary batteries, Hydrometallurgy 47 (1998) 259-271.

[7] X. Li, C. Zhang, S. Zhang, J. Li, B. He, Z. Cui, Preparation of positively charged polyamide composite nanofiltration hollow fiber membrane for lithium and magnesium separation, Desalination 369 (2015) 26-36. 
[8] P. Ma, X.D. Chen, MD.M. Hossain, Lithium extraction from a multicomponent mixture using supported liquid membranes, Sep. Sci.Technol. 35 (2000) 2513-2533.

[9] L. Li, V.G. Deshmane, M.P. Paranthaman, R. Bhave, B.A. Moyer, S. Harrison, Lithium recovery from aqueous resources and batteries: a brief review, Johnson Matthey Technology Review 62 (2018) 161-176.

[10] M. Matsumoto, N. Oku, K. Kondo, Permeation of saccharides through supported ionic liquid membranes containing calixarènes as carriers, Solvent Ext. Res. Dev., Jpn. 20 (2013) 219-224.

[11] A. Dahi, K. Fatyeyeva, D. Langevin, C. Chappey, S.P. Rogalsky, O.P. Tarasyuk, A. Benamor, S. Marais, Supported ionic liquid membranes for water and volatile organic compounds separation : sorption and permeation properties, J. Membr. Sci. 458 (2014) 164-178.

[12] S. Wickramanayake, D. Hopkinson, C. Myers, L. Hong, J. Feng, Y. Seol, D. Plasynski, M. Zeh, D. Luebke, Mechanically robust hollow fiber supported ionic liquid membranes for $\mathrm{CO}_{2}$ separations applications, J. Membr. Sci. 470 (2014) 52-59.

[13] Y. Wang, Y. Liu, J. Han, L. Wang, T. Chen, L. Ni, Selective extraction and preoncentration of trace lead (II) in medicinal plant-based ionic liquid hollow fiber liquid phase microextraction system using dicyclohexyl-18crown-6 as membrane carrier, Anal. Methods 7 (2015) 2339-2346.

[14] J. Abulhassani, J. L. Manzoori, M. Amjadi, Hollow fiber based-liquid phase microextraction using ionic liquid solvent for preconcentration of lead and nickel from environmental and biological samples prior to determination by electrothermal atomic absorption spectrometry, J. Hazard. Mater. 176 (2010) 481-486.

[15] S. Nosrati, N.S. Jayakumar, M.A. Hashim, S. Mukhopadhyay, Performance evaluation of vanadium (IV) transport through supported ionic liquid membrane, J. Taiwan Inst. Chem. E. 44 (2013) 337-342.

[16] Y. Baba, F. Kubota, N. Kamiya, M. Goto, Selective recovery of dysprosium and neodymium ions by a supported liquid membranes based on ionic liquid, Solvent Extr. Res. Dev., Jpn 18 (2011) 193-198.

[17] J. Song, T. Huang, H. Qiu, X. Niu, X-M. Li, Y. Xie, T. He, A critical membrane review on membrane extraction with improved stability: potential application for recycling of metals from city mine, Desalination 440 (2018) 18-38.

[18] A.J.B Kemperman, D. Bagerman, Th. Van Den Boomgard, H. Strathmann, Stability of supported liquid membranes: state of the art, Sep. Sci. Technol. 31 (1996), 2733-2762.

[19] H. Takeuchi, K. Takahashi, W. Goto, Some observations on the stability of supported liquid membranes, J. Membr. Sci. 34 (1987) 19-31.

[20] N.M. Kocherginsky, Q. Yang, L. Seelam, Recent advances in supported liquid membranes technology, Sep. Sci. Technol. 53 (2007) 171-177.

[21] A.P. de los Ríos, F.J. Hernández-Fernández, F. Tomás-Alonso, J.M. Palacios, D. Gómez, M. Rubio, G. Víllora, A SEM-EDX study of highly stable supported liquid membranes based on ionic liquids, J. Membr. Sci. 300 (2007) 88-94. 
[22] L.C. Branco, J.G. Crespo, C.A.M. Afonso, Studies on the selective transport of organic compounds by using ionic liquids as a novel supported liquid membranes, Chem. Eur. J. 8 (2002) 3865-3871.

[23] A.D. Sharma, N.D. Patil, A.W. Patwardhan, R.K. Moorthy, P.K. Ghosh, Synergistic interplay between D2EHPA and TBP towards the extraction of lithium using hollow supported liquid membrane, Sep. Sci. Technol. 51 (2016) 2242-2254.

[24] R. Kopunec, T.N. Manh, Carrier-mediated transport of rare earth elements through liquid membranes. IV. Transport of Sc, Y, Ce, Eu, Gd, Tm, Yb through a supported liquid membrane containing TBP, J. Radioanal. Nucl. Chem. 163 (1992) 131-144.

[25] M.A. Chaudry, S.N. Ahmad, M.Z. Iqbal, B. Ahmad, H.M.A. Karim, Transport of ${ }^{99 m}$ Tc across TBP kerosene oil supported liquid membranes, J. Radioanal. Nucl. Chem. 172 (1993) 371-385.

[26] D. Gao, Y. Guo, X. Yu, S. Wang, T. Deng, Extracting lithium from the high concentration ratio of magnesium and lithium brine using imidazolium-based ionic liquids with varying alkyl chain lengths, J. Chem. Eng. Jpn. 49 (2016) 104-110.

[27] C. Shi, Y. Shing, Y. Jia, Solvent extraction of lithium ions by tri-n-butyl phosphate using a room temperature ionic liquid, J. Mol. Liq. 215 (2016) 640-646.

[28] M. Tariq, M.G. Freire, B. Saramogo, J.A. Coutinho, J.N. Lopes, L.P. Rebelo, Surface tensions of ionic liquids and ionic liquids solutions, Chem. Soc. Rev. 41 (2012) 829-868.

[29] F.J. Hernández-Fernández, A.P. de los Ríos, M. Rubio, F. Tomas-Alonso, D. Gomez, G. Víllora, A novel application of supported liquid membranes based on ionic liquids to the selective simultaneous separation of the substrates and products of a transesterification reaction, J. Membr. Sci. 293 (2007) 73-80.

[30] J.Q. Xue, N.N. Liu, G.P. Li, L.T. Dang, Characterization of a supported ionic liquid membrane used for the removal of cianyde from wastewater, Water Sci. Technol. 76 (2017), 3142-3149.

[31] L. Ropel, L.S. Belvèze, S.N.V.K. Aki, M.A. Stadtherr, J.F. Brennecke, Octanol-water partition coefficient of imidazolium-based ionic liquids, Green Chem. 7 (2005) 83-90.

[32] S.L.I. Toh, J. McFarlane, C. Tsouris, D.W. DePaoli, H. Luo, S. Dai, Room-temperature ionic liquids in liquid-liquid extraction: effets of solubility in aqueous solutions on surface properties, Solvent Extr. Ion Exch. 24 (2006) 33-56.

[33] P.R. Danesi, Separation of metal species by supported liquid membranes, Sep. Sci. Technol. 19 (1984-1985) 857-894.

[34] E.N. Dalal, Calculations of solid surface tensions, Langmuir 3 (1987) 1009-1015.

[35] J.F. Dozol, J. Casas, A. Sastre, Stability of flat sheet supported liquid membranes in the transport of radionuclides from reprocessing concentrate solutions, J. Membr. Sci. 82 (1993) 237-246.

[36] A.P. de los Ríos, F.J. Hernández-Fernádez, F. Tomás-Alonso, J.M. Palacios, D. Gómez, M. Rubio, G. Víllora, A SEM-EDX study of highly stable supported liquid membranes based on ionic liquids, J. Membr. Sci. 300 (2007) 88-94. 
[37] R. Keyes, P. Scovazzo, Ammonium ionic liquid solubilities in water and micellar formation, J. Phys. Chem. B 121 (2017) 7163-7172.

[38] V. Mazan, M.Y. Boltoeva, E.E. Tereshatov, C.M. III. Folden, Mutual solubility of water and hydrophobic ionic liquids in the presence of hydrochloric acid, RSC. Adv. 6 (2016) 5626056270.

[39] D. Dupont, D. Depuydt, K. Binnemans, Overview of the effect of salts on biphasic ionic liquid/water solvent extraction systems: anion exchange, mutual solubility, and thermomorphic properties, J. Phys. Chem. B 119 (2015) 6747-6757.

[40] S. Shahriari, C.M.S.S. Neves, M.G. Freire, J.A.P. Coutinho, Role of the Hofmeister series in the formation of ionic-liquid-based aqueous biphasic systems, J. Phys. Chem. B 116 (2012) 7252-7258.

[41] M.G. Freire, C.M.S.S. Neves, A.M.S. Silva, L.M.N.B.F. Santos, I.M. Marrucho, L.P.N. Rebelo, J.K. Shah, E.J. Magnin, J.A.P. Coutinho, ${ }^{1} \mathrm{H}$ NMR and molecular dynamics evidence for an unexpected interaction on the origin of salting-in/salting-out phenomena, J. Phys. Chem. B 114 (2010), 2004-2014.

[42] M.G. Freire, P.J. Carvalho, A.M.S. Silva, L.M.N.B.F. Santos, L.P.N. Rebelo, I.M. Marrucho, J.A.P. Coutinho, Ion specific effects on the mutual solubilities of water and hydrophobic ionic liquids, J. Phys. Chem. B 113 (2009) 202-211.

[43] R. Zangi, M. Hagen, B.J. Berne, Effect of ions on the hydrophobic interaction between two plates, J. Am. Chem. Soc. 129 (2007) 4678-4686.

[44] A. Hildebrandt, S. Lacorte, D. Barceló, Assessment of priority pesticides, degradation products, and pesticides adjuvants in groundwaters and top soils from agricultural areas of the Ebra river basin, Anal. Bioanal. Chem. 387 (2007) 1459-1468.

[45] S. Endo, A. Pfennigsdorff, K-U. Goss, Salting-out effect in aqueous $\mathrm{NaCl}$ solutions: trends with side and polarity of solute molecules, Environ. Sci. Technol. 46 (2012) 1496-1503.

[46] R-C. Wang, Y-C. Lin, S-H. Wu, A novel recovery process of metal value from the cathode active materials of the lithium-ion secondary batteries, Hydrometallurgy 99 (2009) 194-201.

[47] N.A. Hashim, Y. Liu, K. Li, Stability of PVDF hollow fibre membranes in sodium hydroxide aqueous solutions, Chem. Eng. Sci. 66 (2011) 1565-1575.

[48] M.F. Rabuni, N.M.N. Sulaiman, M.K. Aroua, N.A. Hashim, Effects of alkaline environments at mild conditions on the stability of PVDF membrane: an experimental study, Ind. Eng. Chem. Res. 52 (2013) 15874-15882.

[49] X. Yang, Q. Zhang, Z. Wang, S. Li, Q. Xie, Z. Huang, S. Wang, Synergistic extraction of gold (I) from aurocyanide solution with the mixture of primary amine N1923 and bis(2ethylhexyl)sulfoxide in supported liquid membrane, J. Membr. Sci. 540 (2017) 174-182.

[50] L. Zhang, L. Li, D. Shi, J. Li, X. Peng, F. Nie, Selective extraction of lithium from alkaline brine using HBTA-TOPO synergistic extraction system, Sep. Purif. Technol. 188 (2017) 167173.

[51] S. Tsuchiya, Y. Nakatani, R. Ibrahim, S. Ogawa, Highly efficient separation of lithium chloride from seawater, J. Am. Chem. Soc. 124 (2002) 4936-4937. 
[52] M. Joulié, R. Laucournet, E. Billy, Hydrometallurgical process for the recovery of high value metals from spent lithium nickel cobalt aluminum oxide based lithium-ion batteries, J. Power Sources 247 (2014) 551-555.

[53] B. Swain, C. Mishra, J. Jeong, J-C. Lee, H.S. Hong, B.D. Pandey, Separation of Co (II) and Li (I) with Cyanex 272 using hollow fiber supported liquid membrane: A comparison with flat sheet supported liquid membrane and dispersive solvent extraction process, Chem. Eng. J. 271 (2015) 61-70.

[54] S. Sakultung, K. Pruksathorn, M. Hunsom, Simultaneous recovery of valuable metals from spent mobile phone battery by an acid leaching process, Korean J. Chem. Eng. 24 (2007) 272-277.

[55] R. Golmohammadzadeh, F. Faraji, F. Rashchi, Recovery of lithium and cobalt from spent lithium ion batteries (LIBs) using organic acids as leaching reagents: A review, Resour. Conser. Recycl. 136 (2018) 418-435.

[56] B. Onghena, S. Valgaeren, T. Vander Hoogerstraete, K. Binnemans, Cobalt (II)/Nickel (II) separation from sulfate media by solvent extraction with an undiluted quaternary phosphonium ionic liquid, RSC Adv. 7 (2017) 35992-35999.

[57] A.P. De los Ríos, F.J. Hernández-Fernández, L.J. Lozano, S. Sánchez-Segado, A. GinestáAnzola, C. Godínez, F. Tomás-Alonso, J. Quesada-Medina, On the selective separation of metal ions from hydrochloride aqueous solution by pertraction through supported ionic liquid membranes, J. Membr. Sci. 444 (2013) 469-481.

[58] E. Jean, D. Villemin, M. Hlaibic, L. Lebruna, Heavy metal ions extraction using new supported liquid membranes containing ionic liquid as carrier, Sep. Purif. Technol. 201 (2018) 1-9.

[59] P. Dżygiel, P. Wieczorek, Supported liquid membranes and their modifications: definition, classification, theory, stability, application and perspectives, in: V.S. Kislik (Ed.), Liquid Membranes, Elsevier, Amsterdam, 2010, pp 73-140.

[60] R.A. Robinson, J.B. Macaskill, Osmotic coefficients of aqueous sodium carbonate at $25^{\circ} \mathrm{C}$, Journal of Solution Chemistry, 8 (1979) 35-40.

[61] R.M. Izatt, J.D. Lamb, R.T. Hawkins, P.R. Brown, S.R. Izatt, J.C. Christensen, Selective M $^{+}$ $\mathrm{H}^{+}$coupled transport of cations through a liquid membrane by macrocyclic calixarene ligands, J. Am. Chem. Soc. 105 (1983) 1782-1785.

[62] J.D. Lamb, J.J Christensen, S.R. Izatt, K. Bedke, M.S. Astin, R.M. Izatt, Effects of salts concentration and anion on the rate of carrier-facilitated transport of metal cations through bulk liquid membranes containing crown-ethers, J. Am. Chem. Soc. 102 (1980) 3399-3403.

[63] F. Caracciolo, E.L. Cussler, D.F. Evans, Membranes with common ion pumping, AIChE J. 21 (1975) 160-167. 